\title{
Laparoscopy in management of appendicitis in high-, middle-, and low-income countries: a multicenter, prospective, cohort study
}

\author{
GlobalSurg Collaborative ${ }^{1}$
}

Received: 20 June 2017 / Accepted: 12 January 2018 / Published online: 5 April 2018

(c) The Author(s) 2018

\begin{abstract}
Background Appendicitis is the most common abdominal surgical emergency worldwide. Differences between high- and low-income settings in the availability of laparoscopic appendectomy, alternative management choices, and outcomes are poorly described. The aim was to identify variation in surgical management and outcomes of appendicitis within low-, middle-, and high-Human Development Index (HDI) countries worldwide.

Methods This is a multicenter, international prospective cohort study. Consecutive sampling of patients undergoing emergency appendectomy over 6 months was conducted. Follow-up lasted 30 days.

Results 4546 patients from 52 countries underwent appendectomy ( 2499 high-, 1540 middle-, and 507 low-HDI groups). Surgical site infection (SSI) rates were higher in low-HDI (OR 2.57, 95\% CI 1.33-4.99, $p=0.005$ ) but not middle-HDI countries (OR 1.38, 95\% CI 0.76-2.52, $p=0.291$ ), compared with high-HDI countries after adjustment. A laparoscopic approach was common in high-HDI countries $(1693 / 2499,67.7 \%)$, but infrequent in low-HDI $(41 / 507,8.1 \%)$ and middle-HDI (132/1540, $8.6 \%$ ) groups. After accounting for case-mix, laparoscopy was still associated with fewer overall complications (OR 0.55 , $95 \%$ CI $0.42-0.71, p<0.001)$ and SSIs (OR $0.22,95 \%$ CI $0.14-0.33, p<0.001)$. In propensity-score matched groups within low-/middle-HDI countries, laparoscopy was still associated with fewer overall complications (OR 0.23 95\% CI 0.11-0.44) and SSI (OR $0.2195 \%$ CI 0.09-0.45).

Conclusion A laparoscopic approach is associated with better outcomes and availability appears to differ by country HDI. Despite the profound clinical, operational, and financial barriers to its widespread introduction, laparoscopy could significantly improve outcomes for patients in low-resource environments.
\end{abstract}

Trial registration: NCT02179112.

Keywords Appendicitis · Appendectomy · Global surgery · Laparoscopic · Operative standards · Postoperative care · Postoperative complications $\cdot$ Surgical site infection

The global burden of diseases requiring emergency surgery is poorly described and represents a significant health problem [1]. Most of the world's population do not have access

Collaborating members are shown in Acknowledgements.

Electronic supplementary material The online version of this article (https://doi.org/10.1007/s00464-018-6064-9) contains supplementary material, which is available to authorized users.

GlobalSurg Collaborative enquiry@globalsurg.org

http://www.globalsurg.org

1 NIHR Unit on Global Surgery (Universities of Birmingham, Edinburgh and Warwick), University of Edinburgh, Royal Infirmary of Edinburgh, Edinburgh EH16 4SA, UK to safe, affordable and timely surgery, with access inequitably distributed in favor of high Human Development Index (HDI) countries [2]. It is estimated that in 2010, approximately 17 million deaths resulted from conditions requiring surgical care, far greater than the combined burden of HIV/ AIDs, malaria, and tuberculosis [3]. There is an urgent need to increase access to surgical treatment across the world.

Appendicitis is one of the commonest diseases requiring emergency abdominal surgery, yet little data exist to allow comparison of management and outcomes at a patient level globally [4]. Recently published trends predict a significant increase in the prevalence of appendicitis in newly industrialized countries [5]. Data from the Global Burden of Disease Study (2016) show a higher prevalence of appendicitis in lower socio-economic countries, together with a greater 
proportion of years-of-life-lost as a result of the disease [6]. Appendicitis is usually treated with surgery, although management purely with antibiotics has been investigated [7]. Appendectomy can be performed by a traditional open procedure, but a laparoscopic approach has become common in many countries [8]. Significant variation in practice still exists in high-income settings [9].

The role of laparoscopy in low-resource healthcare settings has been debated [10]. Those arguing against its use suggest that the required initial financial and training investment, together with the on-going costs of equipment upkeep and consumables, make it unviable when compared to relatively straightforward open surgery. This argument has resonance: when a healthcare system is struggling to deliver basic surgical procedures, the introduction of a more complex intervention must be considered carefully. On the other hand, there are broad advantages to having laparoscopy available, particularly the ability to perform diagnostic laparoscopy in the absence of expensive CT imaging. Lower postoperative complication rates [9] and consequent healthcare costs are commonly reported to be associated with laparoscopic appendectomy. Whether laparoscopy has the same advantage in low-resource settings is unknown.

The GlobalSurg Collaborative has recently demonstrated the feasibility of conducting international data collection in low-resource settings $[4,11]$. Using these approaches, this study aimed to investigate the surgical management of appendectomy worldwide, including the use of laparoscopy, and to examine outcomes following surgery.

\section{Methods}

\section{Study setting}

A collaborative, international, multicenter, prospective, observational cohort study was conducted according to a pre-specified, published protocol (ClinicalTrials.gov identifier: NCT02179112) [12]. The collaborative network methodology has been described elsewhere [13]. Briefly, the study was conducted by teams of local investigators coordinated by a national lead investigator. Investigators were recruited via the GlobalSurg network and through dissemination on social media and other personal contacts. Consecutive sampling of patients undergoing emergency abdominal surgery was undertaken during 2 -week periods within a 6-month study window. Investigators in a hospital could choose one or multiple 2 -week periods. There was an absolute requirement for all cases in the chosen period(s) to be included, but no minimum number set to avoid bias against smaller centers. A UK National Health Service Research Ethics review considered this study exempt from formal research registration (South East Scotland Research
Ethics Service, reference NR/1404AB12); individual centers obtained their own audit, ethical or institutional approval. This study is reported according to the Strengthening the Reporting of Observational Studies in Epidemiology (STROBE) guidelines [14]. Pre-specified sub-group analyses included the examination of patients undergoing appendectomy as compared with other abdominal surgical procedures. At each participating center, data collection was performed by teams following the same standardized protocol [12].

\section{Patients and procedures}

The study inclusion period was 01 July 2014 to 31 December 2014. Consecutive patients undergoing emergency appendectomy were eligible for inclusion. No limits were placed on age or operative approach. Emergency surgery was defined as any unplanned, non-elective operation, including re-operation after a previous procedure. Elective (planned) or semi-elective procedures (where a patient initially admitted as an emergency was then discharged from hospital and re-admitted at later time for surgery) were excluded.

\section{Data}

Data were selected to be objective, standardized, easily transcribed and internationally relevant, to maximize record completion and accuracy. Patients were followed for 30 days after surgery or for the length of their inpatient stay where follow-up was not feasible. Records were uploaded by local investigators to a secure online website, provided using the Research Electronic Data Capture (REDCap) system [15]. The lead investigator at each site was responsible for "signing off" patient records. Data were checked with primary data sources if necessary. The local lead was responsible for ensuring consecutive sampling (i.e., no excluded cases) for each site. The submitted data were then checked centrally and where missing data were identified, the local lead investigator was contacted and asked to investigate. Once vetted, the record was accepted into the dataset for analysis.

Patient variables included age, gender, American Society of Anesthesiologists (ASA) physical status classification system, diabetes history, smoking and diagnostic category. Service variables included use of the WHO surgical safety checklist, the experience of surgeon/anesthetist, and compliance with selected evidence-based standards. Prophylactic antibiotic use was defined as antibiotics administered either at induction, or during surgery but before opening of a contaminated space. 


\section{Outcome variables}

The primary outcome measure was overall complication rate, defined using the Clavien-Dindo grade occurring within 30 days of the index operation. The criteria required for each outcome were defined a priori in the protocol [12]. Major complication (Clavien-Dindo IV) was defined as a life-threatening illness requiring critical care management. In low-resource settings, investigators could report "complication requiring critical care, but facilities unavailable."

The US Centre for Disease Control and Prevention (CDC) definitions for SSI and organ space infection (OSI) were used [16]. SSI: one of (1) purulent drainage from the incision; (2) at least two of following: pain or tenderness, localized swelling, redness, heat, fever, and the incision is opened deliberately to manage infection; (3) wound organisms AND pus cells from aspirate/swab. OSI: intra-abdominal/ pelvic detected clinically/symptomatically, radiologically, or intra-operatively.

\section{Power considerations}

The sample size was limited by practical factors and estimation of power by uncertainty over critical quantities such as clustering and variation by diagnosis. An indicative calculation for overall complication rate showed that considerable precision was likely with 520 patients per HDI comparison group (a 6\% point difference in overall complication rate; baseline rate $16 \%$ with alpha $=0.05$, beta $=0.2$, and accounting for missing data/loss to follow-up).

\section{Statistical analysis}

Variation across different international health settings was assessed by stratifying participating centers by country into three tertiles according to HDI rank. This is a composite statistic of life expectancy, education, and income indices published by the United Nations (http://hdr.undp.org/en/stati stics). Differences between HDI tertiles were initially tested with the Pearson chi-squared and Kruskal-Wallis tests for categorical and continuous variables respectively.

Multivariable binary logistic regression models were constructed to adjust for case-mix and measures of hospital facilities and service, to explore the nature of differences in outcome. Subsequently, three-level hierarchical multivariable logistic regression models were made to account for hospital- and country-level variation ("hospital" and "country" as random effects with constrained gradients). Variable selection was incremental and accounted for both clinical and statistical significances. Model fit was guided log-likelihood methods including the Akaike Information Criterion (AIC). Discrimination was defined by the areaunder-the receiver-operator-curve (c-statistic). Calibration across the range of observed probabilities was checked. All two-way interactions were investigated. Bayesian simulation methods are described in the supplementary digital content.

In a further propensity-score matched study, patients from low- and middle-HDI countries were analyzed separately to those from high-HDI countries. Patients who had undergone laparoscopic surgery were matched with those who underwent open surgery using a "nearest neighbor" approach, based on probabilities of group membership determined with multivariable logistic regression. The matching algorithm used age, gender, smoking status, ASA score, and perforation status. Pre- and post-matching balance was checked for all relevant variables.

All analyses were undertaken using the R Foundation Statistical Program (R 3.1.1, R Foundation for Statistical Computing) and Stan (Stan: A C++ Library for Probability and Sampling, Version 2.10.0. URL http://mc-stan.org/).

\section{Results}

4546 patients underwent laparoscopic or open appendectomy for acute appendicitis over the data collection period.

\section{Demographics}

Patients were from 52 countries with high-HDI $(n=2499)$, middle-HDI $(n=1540)$, and low-HDI $(n=507)$ groups (Table 1). Patients in low-HDI countries were younger (Pearson's $\chi^{2}$ test, $\left.p<0.001\right)$ and more likely to be male [low-HDI (295/507, 58\%), middle-HDI (783/1540, 51\%), high-HDI (1344/2499, 54\%), $p=0.012$ ]. There were numerically more patients considered to have severe systemic disease (ASA 3 or greater) in the low-HDI group $(p=0.021)$.

\section{Surgical characteristics}

There were clear differences in management between HDI groups (Table 1). A laparoscopic approach was used in $67.7 \%$ of patients in the high-HDI group and in $<10 \%$ in the low- and middle-HDI groups (Pearson's $\chi^{2}$ test, $p<0.001$ ). There was more operating through the night in low- and middle-HDI groups (Pearson's $\chi^{2}$ test, $p<0.001$ ), while more patients were operated upon $>24 \mathrm{~h}$ after admission in high-HDI countries. Seniority of both the surgeon and anesthetist was higher in high-HDI countries. Prophylactic antibiotics and use of the WHO surgical safety checklist was less common in low- and middle-HDI groups.

\section{Outcomes}

In univariable analyses, associations were seen between HDI and overall and minor complications, as well as surgical site 
Table 1 Patient and operative characteristics

\begin{tabular}{|c|c|c|c|c|}
\hline & \multicolumn{3}{|c|}{ Human development index (HDI) } & \multirow[t]{2}{*}{$p$ Value } \\
\hline & $\operatorname{High}(n=2499)$ & Middle $(n=1540)$ & Low $(n=507)$ & \\
\hline \multicolumn{5}{|l|}{ Age in completed years } \\
\hline Mean (SD) & $31.2(18.2)$ & $26.9(14.6)$ & $24.1(12.1)$ & $<0.001$ \\
\hline \multicolumn{5}{|l|}{ Gender } \\
\hline Male & $1344(53.8)$ & $783(50.8)$ & $295(58.2)$ & 0.012 \\
\hline Female & $1155(46.2)$ & $757(49.2)$ & $212(41.8)$ & \\
\hline \multicolumn{5}{|l|}{ Diabetes history } \\
\hline No & $2435(97.4)$ & $1493(96.9)$ & $489(96.4)$ & 0.390 \\
\hline Yes & $64(2.6)$ & $47(3.1)$ & $18(3.6)$ & \\
\hline \multicolumn{5}{|l|}{ Smoking currently } \\
\hline No & $1977(79.1)$ & $1295(84.1)$ & $446(88.0)$ & $<0.001$ \\
\hline Yes & $521(20.8)$ & $244(15.8)$ & $60(11.8)$ & \\
\hline Missing & $1(0.0)$ & $1(0.1)$ & $1(0.2)$ & \\
\hline \multicolumn{5}{|l|}{ ASA score } \\
\hline 1 & $1724(69.0)$ & $1098(71.3)$ & $344(67.9)$ & 0.021 \\
\hline 2 & $613(24.5)$ & $332(21.6)$ & $102(20.1)$ & \\
\hline$\geq 3$ & $104(4.2)$ & $74(4.8)$ & $33(6.5)$ & \\
\hline Missing & $58(2.3)$ & $36(2.3)$ & $28(5.5)$ & \\
\hline \multicolumn{5}{|l|}{ Procedure start time } \\
\hline 0800-1800 (daytime) & $1345(53.8)$ & $615(39.9)$ & $188(37.1)$ & $<0.001$ \\
\hline 1800-2200 (evening) & $616(24.6)$ & $412(26.8)$ & $137(27.0)$ & \\
\hline 2200-0800 (night-time) & $538(21.5)$ & $513(33.3)$ & $182(35.9)$ & \\
\hline \multicolumn{5}{|l|}{ Surgical safety checklist used } \\
\hline No, not available in this hospital & $182(7.3)$ & $570(37.0)$ & $187(36.9)$ & $<0.001$ \\
\hline No, but available in this hospital & $35(1.4)$ & $103(6.7)$ & $161(31.8)$ & \\
\hline Yes & $2282(91.3)$ & $867(56.3)$ & $159(31.4)$ & \\
\hline \multicolumn{5}{|l|}{ Prophylactic antibiotics } \\
\hline No & $223(8.9)$ & $205(13.3)$ & $62(12.2)$ & $<0.001$ \\
\hline Yes & $2276(91.1)$ & $1335(86.7)$ & $445(87.8)$ & $<0.001$ \\
\hline \multicolumn{5}{|l|}{ Senior surgeon $>5$ years training } \\
\hline No & $108(4.3)$ & $769(49.9)$ & $210(41.4)$ & $<0.001$ \\
\hline Yes & $2391(95.7)$ & $770(50.0)$ & $297(58.6)$ & \\
\hline Missing & $0(0.0)$ & $1(0.1)$ & $0(0.0)$ & \\
\hline \multicolumn{5}{|l|}{ Senior anesthetist $>5$ years training } \\
\hline No & $115(4.6)$ & $789(51.2)$ & $265(52.3)$ & $<0.001$ \\
\hline Yes & $2384(95.4)$ & $751(48.8)$ & $242(47.7)$ & \\
\hline \multicolumn{5}{|l|}{ Laparoscopic approach } \\
\hline No & $806(32.3)$ & $1408(91.4)$ & $466(91.9)$ & $<0.001$ \\
\hline Yes & $1693(67.7)$ & $132(8.6)$ & $41(8.1)$ & \\
\hline \multicolumn{5}{|l|}{ Perforated viscus } \\
\hline No & $2150(86.0)$ & $1380(89.6)$ & $394(77.7)$ & $<0.001$ \\
\hline Yes & 348 (13.9) & $159(10.3)$ & $109(21.5)$ & \\
\hline Missing & $1(0.0)$ & $1(0.1)$ & $4(0.8)$ & \\
\hline
\end{tabular}

Data are $n(\%)$ unless otherwise stated

$S D$ standard deviation and OSIs (Table 2). There was no strong association between HDI and reintervention, major complication, or death.

The overall complication rate was higher in low-HDI (odds ratio (OR) 1.55, 95\% confidence interval (CI)
$1.19-1.99, p=0.001)$ and middle-HDI (OR 1.24, 95\% CI $1.03-1.49, p=0.020)$ countries compared with the highHDI group (Tables 2, 3). When the analysis was adjusted in a multilevel model accounting for patient, disease, and 
Table 2 Outcomes

\begin{tabular}{|c|c|c|c|c|}
\hline & \multicolumn{4}{|c|}{ Human development index (HDI) } \\
\hline & High $(n=2499)$ & Middle $(n=1540)$ & Low $(n=507)$ & $p$ Value \\
\hline \multicolumn{5}{|c|}{ Overall complications (Clavien-Dindo I, II, III, IV, or V) } \\
\hline No & $2182(87.3)$ & $1303(84.7)$ & $414(81.7)$ & \multirow[t]{3}{*}{0.001} \\
\hline Yes & $317(12.7)$ & $235(15.3)$ & $93(18.3)$ & \\
\hline Missing & $0(0.0)$ & $2(0.1)$ & $0(0.0)$ & \\
\hline \multicolumn{5}{|c|}{ Minor complication (Clavien-Dindo I/II) } \\
\hline No & $2219(88.9)$ & $1314(86.1)$ & $423(84.1)$ & \multirow[t]{3}{*}{0.002} \\
\hline Yes & $278(11.1)$ & $212(13.9)$ & $80(15.9)$ & \\
\hline Missing & $2(0.1)$ & $14(0.9)$ & $4(0.8)$ & \\
\hline \multicolumn{5}{|c|}{ Reintervention (Clavien-Dindo III) } \\
\hline No & $2431(97.3)$ & $1501(97.6)$ & $494(97.4)$ & \multirow[t]{3}{*}{0.828} \\
\hline Yes & $68(2.7)$ & $37(2.4)$ & $13(2.6)$ & \\
\hline Missing & $0(0.0)$ & $2(0.1)$ & $0(0.0)$ & \\
\hline \multicolumn{5}{|c|}{ Major complication (Clavien-Dindo IV) } \\
\hline No & $2474(99.0)$ & $1520(98.8)$ & $498(98.2)$ & \multirow[t]{3}{*}{0.325} \\
\hline Yes & $25(1.0)$ & $18(1.2)$ & $9(1.8)$ & \\
\hline Missing & $0(0.0)$ & $2(0.1)$ & $0(0.0)$ & \\
\hline \multicolumn{5}{|c|}{ Surgical site infection (SSI) } \\
\hline No & $2389(95.6)$ & $1340(88.0)$ & $432(85.2)$ & \multirow[t]{3}{*}{$<0.001$} \\
\hline Yes & $109(4.4)$ & $183(12.0)$ & $75(14.8)$ & \\
\hline Missing & $1(0.0)$ & $1(0.1)$ & $0(0.0)$ & \\
\hline \multicolumn{5}{|c|}{ Organ/space infection (OSI) } \\
\hline No & $2397(96.0)$ & $1486(96.4)$ & $494(97.4)$ & \multirow[t]{3}{*}{0.023} \\
\hline Yes & $101(4.0)$ & $39(2.7)$ & $13(2.6)$ & \\
\hline Missing & $1(0.0)$ & $15(1.0)$ & $0(0.0)$ & \\
\hline \multicolumn{5}{|c|}{ Length of stay after surgery (days) } \\
\hline Mean (SD) & $3(3.4)$ & $2.9(3.2)$ & $4.1(4.7)$ & $<0.001$ \\
\hline \multicolumn{5}{|c|}{ 30-day mortality } \\
\hline Alive & 2496 (99.9) & 1532 (99.5) & $504(99.4)$ & \multirow[t]{3}{*}{0.061} \\
\hline Dead & $3(0.1)$ & $2(0.1)$ & $3(0.6)$ & \\
\hline Missing & $0(0.0)$ & $6(0.4)$ & $0(0.0)$ & \\
\hline
\end{tabular}

Data are $n(\%)$ unless otherwise stated

$S D$ standard deviation

hospital structural factors, there was no independent association between overall complications and HDI group.

A further prominent association was seen with more surgical site infection (SSI) in low-HDI (OR 3.81, 95\% CI 2.78-5.19, $p<0.001$ ) and middle-HDI (OR 2.99, 95\% CI 2.34-3.84, $p<0.001$ ) compared with high-HDI (Tables 2 , $4)$. In the multilevel model, the association persisted in low-HDI (OR 2.57, 95\% CI 1.33-4.99, $p=0.005$ ) but not middle-HDI (OR 1.38, 95\% CI 0.76-2.52, $p=0.291$ ) countries.

There was no association in multilevel models between HDI and OSI (Table S1, Supplemental Digital Content).

Determining any influence of laparoscopy compared with an open approach is difficult given the inherent selection bias and the lower availability in low-HDI and middle-HDI countries. This is highlighted by the different populations undergoing laparoscopic compared with open procedures (Table S2, Supplemental Digital Content). Differences in the laparoscopic group included more females, lower ASA score, a greater likelihood of senior surgeon and anesthetist involvement, and lower perforation rates. Two approaches were taken to attempt to reduce the effect of this imbalance: multilevel logistic regression modeling and a propensityscore matched analysis.

After accounting for case-mix imbalance, laparoscopy was still associated with significantly fewer complications (OR 0.55, 95\% CI 0.42-0.71, $p<0.001$, Table 3 ) and SSIs (OR 0.22 , 95\% CI $0.14-0.33, p<0.001$, Table 4). To try and communicate these differences more meaningfully, a simple simulation was performed using different patient baseline characteristics (Table 5). This analysis shows an absolute risk reduction (ARR) in overall complication 
Table 3 Overall complications

Overall complications

No Yes

HDI tertile

High

Middle

Low

Age in completed years

Mean (SD)

Gender

Male

Female

Diabetes history

No

Yes

Smoking currently

No

Yes

ASA score

1

2

$\geq 3$

Procedure start time

0800-1800 (daytime)

1800-2200 (evening)

2200-0800 (night-time)

Surgical safety checklist used

No, not available in this hospital

No, but available in this hospital

Yes

Prophylactic antibiotics

No

Yes

Senior surgeon $>5$ years training

No

Yes

Senior anesthetist $>5$ years training

No

Yes

Laparoscopic approach

No

Yes

Perforated viscus

No

Yes
$2182(56.0)$

$1303(33.4)$

$414(10.6)$

$28.2(16)$

$2069(53.1)$

$1830(46.9)$

3805 (97.6)

$94(2.4)$

$3208(82.3)$

$688(17.7)$

$2790(73.6)$

$850(22.4)$

$151(4.0)$

1854 (47.6)

985 (25.3)

$1060(27.2)$

$781(20.0)$

$250(6.4)$

$2868(73.6)$

$422(10.8)$

$3477(89.2)$

$920(23.6)$

$2978(76.4)$

$980(25.1)$

$2919(74.9)$

$2222(57.0)$

$1677(43.0)$

$3474(89.2)$

$419(10.8)$
$317(49.1)$

$235(36.4)$

$93(14.4)$

$1.24(1.03-1.49, p=0.020)$

$0.91(0.56-1.48, p=0.701)$

$1.55(1.19-1.99, p=0.001)$

$1.44(0.82-2.54, p=0.209)$

$33.3(19.5)$

$1.02(1.01-1.02, p<0.001)$

$1.01(1.01-1.02, p<0.001)$

$351(54.4)$

$294(45.6)$

$0.95(0.80-1.12, p=0.523)$

$0.98(0.82-1.19, p=0.873)$

$610(94.6)$

$35(5.4)$

$2.32(1.54-3.42, p<0.001)$

$1.27(0.80-2.01, p=0.315)$

$508(78.8)$

$137(21.2)$

$1.26(1.02-1.54, p=0.029)$

$0.96(0.76-1.23, p=0.770)$

$375(59.4)$

$196(31.1)$

$60(9.5)$

$1.72(1.42-2.07, p<0.001)$

$1.42(1.13-1.78, p=0.003)$

$2.96(2.14-4.04, p<0.001)$

$1.64(1.10-2.46, p=0.016)$

$292(45.3)$

$180(27.9)$

$173(26.8)$

$1.16(0.95-1.42, p=0.148)$

$1.04(0.85-1.27, p=0.730)$

157 (24.3)

48 (7.4)

$440(68.2)$

$0.96(0.67-1.35, p=0.799)$

$0.79(0.48-1.30, p=0.352)$

$0.76(0.63-0.93, p=0.008)$

$0.84(0.59-1.19, p=0.327)$

$67(10.4)$

$578(89.6)$

$1.05(0.80-1.39, p=0.741)$

$0.99(0.72-1.37, p=0.974)$

167 (25.9)

$478(74.1)$

$0.88(0.73-1.07, p=0.207)$

$1.05(0.78-1.42, p=0.745)$

189 (29.3)

$456(70.7)$

$0.81(0.67-0.98, p=0.025)$

$1.02(0.75-1.39, p=0.901)$

457 (70.9)

$188(29.1)$

$0.55(0.45-0.65, p<0.001)$

$0.55(0.42-0.71, p<0.001)$

$450(69.8)$

$195(30.2)$

Data are $n(\%)$ unless otherwise stated. Hospitals $=339$, countries $=52$. AIC $=3339.1$. c-statistic $=0.790$

$O R$ odds ratio, $C I$ confidence interval, $H D I$ human development index, $A S A$ American Association of Anesthesiologists risk score, $S D$ standard deviation 
Table 4 Surgical site infection

Surgical site infection

No Yes

HDI tertile

High

Middle

Low

Age in completed years

Mean (SD)

Gender

Male

Female

Diabetes history

No

Yes

Smoking currently

No

Yes

ASA score

1

2

$\geq 3$

Procedure start time

0800-1800 (daytime)

1800-2200 (evening)

2200-0800 (night-time)

Surgical safety checklist used

No, not available in this hospital

No, but available in this hospital

Yes

Prophylactic antibiotics

No

Yes

Senior surgeon $>5$ years training

No

Yes

Senior anesthetist $>5$ years training

No

Yes

Laparoscopic approach

No

Yes

Perforated viscus

No

Yes
$2389(57.4)$

$1340(32.2)$

$432(10.4)$

$28.6(16.4)$

$2205(53.0)$

$1956(47.0)$

$4058(97.5)$

$103(2.5)$

$3415(82.1)$

$743(17.9)$

2937 (72.6)

$934(23.1)$

$172(4.3)$

1975 (47.5)

1057 (25.4)

$1129(27.1)$

826 (19.9)

$253(6.1)$

$3082(74.1)$

$445(10.7)$

$3716(89.3)$

943 (22.7)

$3217(77.3)$

$1006(24.2)$

$3155(75.8)$

$2338(56.2)$

$1823(43.8)$

3654 (87.9)

$502(12.1)$
109 (29.7)

183 (49.9)

75 (20.4)

$2.99(2.34-3.84, p<0.001)$

$1.38(0.76-2.52, p=0.291)$

$3.81(2.78-5.19, p<0.001)$

$2.57(1.33-4.99, p=0.005)$

$32.8(18.9)$

$1.01(1.01-1.02, p<0.001)$

$1.01(1.01-1.02, p=0.001)$

$208(56.7)$

$159(43.3)$

$0.86(0.69-1.07, p=0.175)$

$0.95(0.74-1.22, p=0.666)$

$341(92.9)$

$26(7.1)$

$3.00(1.89-4.61, p<0.001)$

$1.45(0.83-2.52, p=0.189)$

$287(78.2)$

$80(21.8)$

$213(58.7)$

111 (30.6)

39 (10.7)

$1.64(1.28-2.08, p<0.001)$

$3.13(2.13-4.50, p<0.001)$

$1.42(1.05-1.94, p=0.025)$

$1.82(1.10-3.00, p=0.020)$

$162(44.1)$

105 (28.6)

$100(27.2)$

$1.21(0.93-1.56, p=0.144)$

$1.08(0.83-1.40, p=0.562)$

$108(29.4)$

45 (12.3)

$1.36(0.93-1.97, p=0.108)$

$0.92(0.51-1.65, p=0.771)$

$214(58.3)$

$0.53(0.42-0.68, p<0.001)$

$1.00(0.64-1.54, p=0.987)$

43 (11.7)

$324(88.3)$

$0.90(0.65-1.27, p=0.545)$

$0.99(0.66-1.50, p=0.976)$

138 (37.6)

$229(62.4)$

$0.49(0.39-0.61, p<0.001)$

$0.86(0.60-1.23, p=0.395)$

154 (42.0)

$213(58.0)$

$0.44(0.35-0.55, p<0.001)$

$0.86(0.60-1.24, p=0.428)$

$326(88.8)$

$41(11.2)$

$0.16(0.11-0.22, p<0.001)$

$0.22(0.14-0.33, p<0.001)$

$258(70.5)$

$108(29.5)$
$3.05(2.38-3.88, p<0.001)$

$3.36(2.47-4.59, p<0.001)$

Data are $n(\%)$ unless otherwise stated. Hospitals $=339$, countries $=52$. AIC $=2164$. c-statistic $=0.849$

$O R$ odds ratio, $C I$ confidence interval, $H D I$ human development index, $A S A$ American Association of Anesthesiologists risk score, $S D$ standard deviation 
Table 5 Overall complications (top) and SSI (bottom) simulation

\begin{tabular}{|c|c|c|c|c|c|c|}
\hline & 1 & 2 & 3 & 4 & 5 & 6 \\
\hline HDI group & Low & Low & Middle & Middle & High & High \\
\hline Perforation & No & Yes & No & Yes & No & Yes \\
\hline \multicolumn{7}{|l|}{ Overall complications } \\
\hline $\begin{array}{l}\text { Complication (\%) with open } \\
\text { approach }\end{array}$ & $14.7(9.7-20.9)$ & $37.0(26.8-48.3)$ & $13.0(9.1-17.7)$ & $33.7(24.8-43.9)$ & $13.6(9.6-18.3)$ & $35.0(26.3-44.5)$ \\
\hline $\begin{array}{l}\text { Complication (\%) with lap } \\
\text { approach }\end{array}$ & $8.5(5.1-12.8)$ & $24.0(15.5-34.5)$ & $7.4(4.7-10.9)$ & $21.5(14.1-30.9)$ & $7.8(5.3-10.7)$ & $22.4(15.7-30.1)$ \\
\hline $\begin{array}{l}\text { Absolute risk reduction (\%) open } \\
\text { versus laparoscopic }\end{array}$ & $6.3(3.5-9.6)$ & $13.0(7.7-18.5)$ & $5.6(3.3-8.2)$ & $12.3(7.5-17.1)$ & $5.9(3.3-8.8)$ & $12.6(7.5-18.1)$ \\
\hline Number-needed-to-treat & $16(11-29)$ & $8(6-13)$ & $18(13-31)$ & $9(6-14)$ & $17(12-31)$ & $8(6-14)$ \\
\hline \multicolumn{7}{|l|}{ Surgical site infection (SSI) } \\
\hline SSI (\%) with open approach & $9.8(5.5-15.9)$ & $26.1(15.8-39.2)$ & $5.7(2.9-9.7)$ & $16.6(8.9-26.8)$ & $5.1(2.8-8.0)$ & $15.0(8.7-23.3)$ \\
\hline SSI (\%) with lap approach & $2.4(1.1-4.5)$ & $7.5(3.5-13.6)$ & $1.4(0.6-2.6)$ & $4.4(1.9-8.5)$ & $1.2(0.6-2.1)$ & $3.9(1.9-6.9)$ \\
\hline $\begin{array}{l}\text { Absolute risk reduction (\%) open } \\
\text { versus laparoscopic }\end{array}$ & $7.4(4.1-12.1)$ & $18.6(11.4-27.7)$ & $4.8(2.2-7.4)$ & $12.2(6.6-19.6)$ & $3.9(2.1-6.4)$ & $11.2(6.3-17.4)$ \\
\hline Number-needed-to-treat & $14(9-25)$ & $6(4-9)$ & $21(14-46)$ & $9(6-16)$ & $26(16-48)$ & $9(6-16)$ \\
\hline
\end{tabular}

The multilevel logistic regression models were simulated to convert model coefficients into real-world quantities of interest. The probabilities for different characteristics are shown, together with ARR for open versus laparoscopic. NNT with laparoscopic approach to save a complication. Data are proportion as a percentage $(95 \% \mathrm{CI})$. Baseline covariate levels are age 29 years, gender male, ASA score 1, diabetes no, currently smoking no, checklist no, antibiotics yes, senior surgeon training $>5$ years yes, anesthetics training $>5$ years yes

rate associated with laparoscopy of around $6 \%$ [numberneeded-to-treat $(\mathrm{NNT})=16$ ] in the absence of perforation and $17 \%(\mathrm{NNT}=8)$ when the appendix is perforated across HDI groups. For SSI, the analysis implies a greater potential benefit of laparoscopy in low-HDI (ARR $18.6 \%, 95 \%$ CI 11.4-27.7 with perforation) and middle-income countries (ARR 12.2\%, 95\% CI 6.6-19.6\% with perforation), which is expected given the association of HDI and SSI seen in the multilevel model.

To further explore these relationships, a propensityscore-based matching analysis was performed. Patients were first subset into low-/middle-HDI and high-HDI groups. Using all available independent baseline variables and a nearest neighbor approach, 167 patients in the laparoscopic group were matched to 167 in the open group in the low-/middle-HDI subset (Fig. 1, Tables S3 and S4, Supplemental Digital Content) and 783 matched in the high-HDI group. Balance was more easily achieved in the low-/middle-HDI group, with persistent imbalance only seen for seniority of anesthetist and surgical safety checklist use. Balance using nearest neighbor matching was difficult to achieve in the high-HDI group, reflecting de facto differences in the characteristics of patients offered laparoscopic compared with those undergoing open procedures in practice. Alternative matching procedures were successfully explored, but have not been included for space and clarity. Adjusted logistic regression models were applied to the matched sets to address any residual confounding. In the low-/middle-HDI group, a laparoscopic approach was still associated with fewer overall complications (OR
$0.2395 \%$ CI $0.11-0.44, p<0.001)$, minor complications (OR $0.1695 \%$ CI $0.06-0.35, p<0.001$ ), and episodes of SSI (OR 0.21 95\% CI 0.09-0.45, $p<0.001$ ) (Table S5, Supplemental Digital Content, Fig. 1). Similar results were observed within the matched high-HDI group (Table S6, Supplemental Digital Content).

\section{Discussion}

This is the first patient-level prospective study to describe the surgical approach to appendectomy and the frequency of postoperative complications on a global scale. Our findings reveal clear differences in the management of appendicitis and disparities in complication frequency between different HDI groups, with significantly more wound infections (SSI) in low-HDI versus high-HDI countries. A laparoscopic approach was common in the high-HDI group $(1693 / 2499,67.7 \%)$ but infrequent in low- $(41 / 507,8.1 \%)$ and middle-HDI $(132 / 1540,8.6 \%)$ groups. In analyses that attempted as far as it is possible to account for the inherent selection bias in these observational data, laparoscopy in low-/middle-HDI countries was significantly associated with fewer complications and lower SSI rates.

We have previously shown differences in outcomes after emergency surgery by HDI, with mortality found to be higher in low- and middle-HDI countries compared with high-HDI countries both in adults [4] and children [17]. In the present study, unadjusted analyses show a similar picture. However, in the multivariable analysis for overall 


\begin{tabular}{|c|c|c|}
\hline \multicolumn{3}{|l|}{ High HDI countries } \\
\hline \multirow[t]{2}{*}{ Overall complications (CD I to V) } & Open & $143 / 783$ \\
\hline & Laparoscopic & $68 / 783$ \\
\hline \multirow[t]{2}{*}{ Minor complication (Clavien Dindo I/II) } & Open & $128 / 783$ \\
\hline & Laparoscopic & $63 / 783$ \\
\hline \multirow[t]{2}{*}{ Reintervention (Clavien Dindo III) } & Open & $30 / 783$ \\
\hline & Laparoscopic & $13 / 783$ \\
\hline \multirow[t]{2}{*}{ Major complication (Clavien Dindo IV) } & Open & $13 / 783$ \\
\hline & Laparoscopic & \\
\hline \multirow[t]{2}{*}{ Surgical site infection (SSI) } & Open & $77 / 78$ \\
\hline & Laparoscopic & $12 / 78$ \\
\hline \multirow[t]{2}{*}{ Organ space infection (OSI) } & Open & $41 / 78$ \\
\hline & Laparoscopic & $19 / 783$ \\
\hline \multirow[t]{2}{*}{ 30-day mortality } & Open & \\
\hline & Laparoscopic & $1 / 78$ \\
\hline \multicolumn{3}{|l|}{ Low-/middle-HDI countries } \\
\hline \multirow[t]{2}{*}{ Overall complications (CD I to V) } & Open & $42 / 16$ \\
\hline & Laparoscopic & $13 / 16$ \\
\hline \multirow[t]{2}{*}{ Minor complication (CD I/II) } & Open & $36 / 167$ \\
\hline & Laparoscopic & $8 / 167$ \\
\hline \multirow[t]{2}{*}{ Reintervention (CD III) } & Open & $7 / 16$ \\
\hline & Laparoscopic & $5 / 16$ \\
\hline \multirow[t]{2}{*}{ Major complication (CD IV) } & Open & $5 / 167$ \\
\hline & Laparoscopic & $2 / 167$ \\
\hline \multirow[t]{2}{*}{ Surgical site infection (SSI) } & Open & $31 / 167$ \\
\hline & Laparoscopic & $9 / 16$ \\
\hline \multirow[t]{2}{*}{ Organ space infection (OSI) } & Open & $5 / 167$ \\
\hline & Laparoscopic & $8 / 16$ \\
\hline \multirow[t]{2}{*}{ 30-day mortality } & Open & $1 / 16$ \\
\hline & Laparoscopic & $1 / 16$ \\
\hline
\end{tabular}

Matched multivariable OR $95 \%$ Cl p-value

1.00 (Reference) 0.64 (0.43 to 0.95$)$

1.00 (Reference)

0.69 (0.46 to 1.05$)$

1.00 (Reference)

0.63 (0.30 to 1.29$)$

1.00 (Reference)

0.11 (0.01 to 0.59 )

1.00 (Reference)

0.21 (0.10 to 0.41 )

1.00 (Reference)

0.61 (0.30 to 1.21 )

1.00 (Reference)

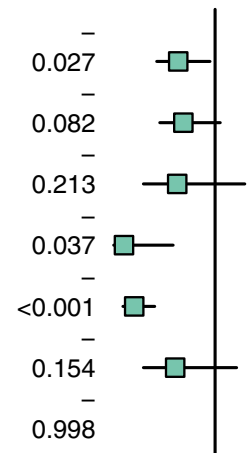

1.00 (Reference)

0.23 (0.11 to 0.44 )

1.00 (Reference)

0.16 (0.06 to 0.35$)$

1.00 (Reference)

0.76 (0.22 to 2.48 )

1.00 (Reference)

0.42 (0.06 to 1.98 )

1.00 (Reference)

0.21 (0.09 to 0.45 )

1.00 (Reference)

$1.80(0.57$ to 6.29$)$

1.00 (Reference)

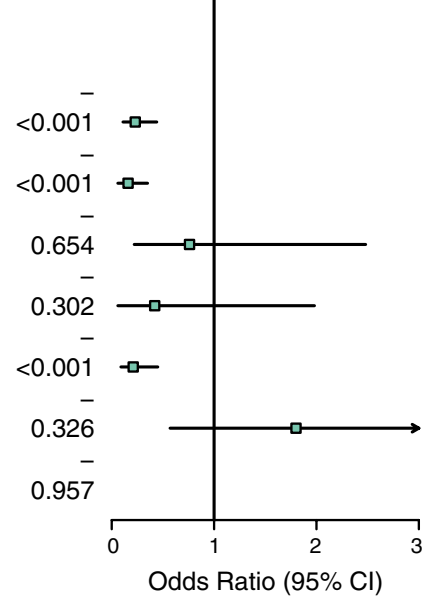

Fig. 1 Odds ratio plot for all outcome measures after propensity score matching by HDI group. $O R$ odds ratio, $C D$ Clavien-Dindo grade, $C I$ confidence interval. Note there was an insufficient number of events to specify models for 30-day mortality

complications, no persistent association was seen with HDI after accounting for case-mix and structural differences. There were persistent differences seen in SSI rates after adjustment. SSI is therefore a phenomenon in which factors not accounted for in our models play an important role. More studies are needed to understand how this can be intervened upon.

It is well established in high-income settings that laparoscopic appendectomy is associated with better outcomes; however, little information exists in low-resource settings [18-21]. Wei et al. undertook a randomized comparison of open and laparoscopic appendectomy and concluded that a laparoscopic approach was associated with lower SSI rates and fewer complications, [18] a finding similar to that observed in the current study. Further advantages include reduced postoperative stay, less postoperative pain, and lower oxidative stress $[19,20]$. In our study, the presence of a perforated appendix was associated with a 3- to 4-fold increase in adverse outcomes in multivariable models, including an increased surgical site and organ space (abscess) infection, findings similar to previous studies [21]. It has been debated whether a laparoscopic approach is always appropriate for patients with more advanced disease and peritonitis; however, evidence does exist supporting a laparoscopy even in complicated cases where reduced infection rates and postoperative length of stay can be achieved [22, 23].

Appendicitis is common in low-resource settings but its incidence varies greatly by country. It is the fourth-most common procedure performed by training surgeons in the College of Surgeons of East, Central and Southern Africa (COSECSA) region [24]. Appendicitis also presents differently in the poorest countries,[25] which is supported in the current study by the higher perforation rate seen in the low-HDI group (21.5\%) compared with high-HDI group (13.9\%). Given traditional assumptions around treatment delay and progression to perforation, this may be due to the well-described first-delay in seeking medical attention in low-HDI settings, compounded by a second-delay in reaching a medical facility that may be many days' travel away [3]. Alternatively, this may represent a pathophysiological distinction between perforated and non-perforated appendicitis,[26] with selection exaggerated in low-resource settings by delays in seeking medical attention arising from 
geographic barriers to access, cultural differences, and the potential out-of-pocket impoverishing or catastrophic costs of surgery discouraging all but the sickest in attending hospital [27, 28].

The increased use of laparoscopy in low-income settings is controversial. In the poorest regions, the provision of any surgical service is extremely difficult and current hightechnology, resource intensive laparoscopy is not feasible. However, our results raise the possibility of a benefit for patients and the healthcare system more widely. Given the higher rates of SSI in some low-income settings, the absolute benefit of laparoscopy is likely to be greater as shown by the simulation results [ARR of SSI in low-HDI countries (18.6\%) compared with high-HDI countries (11.2\%)]. This translates to a NNT with laparoscopic rather than open surgery of 6 to prevent one SSI in low-HDI countries managing perforated appendicitis. Moreover, in the absence of CT imaging, diagnostic laparoscopy can provide an effective way to investigate patients with acute abdominal pain short of the requirement for a full laparotomy.

The major strength of this study is the collection of patient-level prospective data from 52 countries. This unique dataset allows comparison across the HDI spectrum which is rarely possible. A published, detailed protocol translated into major languages ensured consistent data collection across varying regions without the burden of communication barriers. Local validation by leads ensured data accuracy and completeness was high. The interpretation of observational data is always difficult due to the inherent bias implicit in treatment allocation of patients. We have explored both multilevel models accounting for clustering patients in hospitals and countries, and propensity-score-matched models. In the latter, patients within low-/middle-HDI countries undergoing open or laparoscopic approaches were matched using available baseline variables, thus attempting to compare only "similar" patients who had undergone alternative treatments. Good balance was achieved and benefits of laparoscopy continue to be seen.

There are a number of weaknesses associated with our approach. Denominator data at a country level cannot easily be collected using this methodology. The "snapshot" may not accurately reflect overall practice, particularly where there are prominent seasonal effects [29]. We were not able to capture the degree of sepsis beyond the ASA and perforation rates, which may result in residual confounding. Within low-income, rural settings, collection of 30-day follow-up data can be challenging as patients are often discharged to remote regions and therefore cannot return to attend followup clinics. This was minimized by liberal use of telephone follow-up where feasible. A subsequent validation study of this methodology suggests that telephone follow-up is possible in upwards of one-third of included patients. Validation of data entry is challenging particularly where patient record keeping is limited. Collaborators frequently commented that the collected study data were of higher quality than existing hospital data. At each participating center, a lead was appointed to perform data validation and ensure accurate data-entry.

These results have significant implications for policy makers. Variation exists in outcomes after appendectomy across the world, but at least some of that variation may be explained by local surgical infrastructure such as the availability of laparoscopic surgery. Health services are faced with competing priorities and must balance a desire to improve surgical care with the costs of treating, say, malaria. The introduction of any new technology in a resource-poor setting must also be done with care. Recommendations include ensuring the existence of sufficient financial support and organizational systems to address staff training, including biomedical engineering staff to undertake equipment maintenance, and to establish robust, affordable, and sustainable supply chains [10]. A successful implementation of laparoscopic surgery has already been demonstrated at scale in low-resource settings [30].

Future research must focus on identifying innovative, affordable, and safe strategies to implement and scale laparoscopic surgery in low-resource settings. Such adaptive techniques may include gasless laparoscopy, room air insufflation, and development of affordable, reusable instrumentation. In addition, there is an ongoing need to establish robust systems for the continuous measurement of surgical outcomes across the world. High-quality clinical trials relevant to low-HDI countries must be performed to ensure the identification of the most effective treatments, such as how to reduce SSI. Outcomes in surgery will only improve with system-wide improvements across the pre-hospital, hospital, and post-hospital sectors.

This study has shown significant variation in the management and outcomes following appendectomy worldwide. The availability of laparoscopy differs by country HDI, and appears to be significantly associated with better outcomes. There are profound clinical, operational, and financial barriers to the introduction of laparoscopy that if overcome could result in significantly improved outcomes for patients and the wider health system in low-resource environments.

Acknowledgements Organizations assisting in dissemination (alphabetical): Asian Medical Students' Association (AMSA), Association of Surgeons in Training (ASiT), College of Surgeons of East, Central \& Southern Africa (COSECSA), Cutting Edge Manipal, Egyptian Medical Student Research Association (EMRA), International Collaboration For Essential Surgery (ICES), International Federation of Medical Student Associations (IFMSA), Lifebox Foundation, School of Surgery, Student Audit and Research in Surgery (STARSurg), The Electives Network, United Kingdom National Research Collaborative, World Korean Medical Students Association (WKMSA), World Society of Emergency Surgery (WSES), World Surgical Association (WSA). Individuals assisting in dissemination (alphabetical): Douglas 
Bowley, Vimal Gokani, Jaymie Ang Henry, Chia Kong, Chris Lavy, Jane Lim, Laura Luque, Mahiben Maruthappu, Praveen Mogan, Dmitri Nepogodiev, Raza Sayyed, Joseph Shalhoub, Ravi Vohra.

Writing group Thomas M Drake*, Julian Camilleri-Brennan*, Stephen Tabiri, Stuart J Fergusson, Richard Spence, J Edward F Fitzgerald, Aneel Bhangu, Ewen M Harrison (Guarantor), on behalf of the GlobalSurg Collaborative. *Contributed equally.

Steering group (alphabetical) Adesoji O Ademuyiwa, Aneel Bhangu, Thomas M Drake, J Edward F Fitzgerald, Stuart Fergusson, James C Glasbey, Ewen M Harrison, Chetan Khatri, Midhun Mohan, Dmitri Nepogodiev, Kjetil Søreide.

National Leads These individuals were involved in recruitment of multiple centres from the countries listed. Chetan Khatri (Lead Coordinator for GlobalSurg), Neel Gobin (Australia), Ana Vega Freitas (Brazil), Nigel Hall (Canada), Sung-Hee Kim (China, Hong Kong), Ahmed Negida (Egypt), Zahra Jaffry (England) Stephen J Chapman (England), Alexis P Arnaud (France), Stephen Tabiri (Ghana), Gustavo Recinos (Guatemala), Cutting Edge Manipal, Midhun Mohan (India), Radhian Amandito (Indonesia), Marwan Shawki (Iraq), Michael Hanrahan (Ireland), Francesco Pata (Italy), Justas Zilinskas (Lithuania), April Camilla Roslani, Cheng Chun Goh (Malaysia), Adesoji O Ademuyiwa (Nigeria), Gareth Irwin (Northern Ireland), Sebastian Shu, Laura Luque (Peru), Hunain Shiwani, Afnan Altamimi, Mohammed Ubaid Alsaggaf (Saudi Arabia), Stuart J Fergusson (Scotland), Richard Spence, Sarah Rayne (South Africa), Jenifa Jeyakumar (Sri Lanka), Yucel Cengiz (Sweden), Dmitri A Raptis (Switzerland), James C Glasbey (Wales)

Argentina Claudio Fermani, Ruben Balmaceda, Maria Marta Modolo (Hospital Luis Lagomaggiore).

Australia Ewan Macdermid, Neel Gobin, Roxanne Chenn, Cheryl Ou Yong, Michael Edye (Blacktown Hospital), Martin Jarmin, Scott K D'amours, Dushyant Iyer (Liverpool Hospital, The University Of New South Wales), Daniel Youssef, Nicholas Phillips, Jason Brown (Royal Brisbane \& Women's Hospital), Robert George, Cherry Koh, Oliver Warren (The Royal Prince Alfred Hospital, Australia), Isaac Hanley (The Tweed Hospital), Marilla Dickfos (Toowoomba Hospital).

Austria Clemens Nawara, Dietmar Öfner, Florian Primavesi (Department Of Surgery, Paracelsus Medical University Salzburg).

Bangladesh Ashrarur Rahman Mitul, Khalid Mahmud (Dhaka Shishu (Children) Hospital), Margub Hussain, Hafiz Hakim, Tapan Kumar (Dhaka Medical College Hospital), Antje Oosterkamp (Lamb Hospital).

Benin Pamphile A Assouto, Ismail Lawani, Yacoubou Imorou Souaibou (Centre National Hospitalier Et Universitaire Hubert Koutoukou Maga).

Brunei Aung Kyaw Tun, Chean Leung Chong, (Pmmpmhamb Hospital) Giridhar H Devadasar, Chean Leung Chong, Muhammad Rashid Minhas Qadir, (Ssb Hospital), Kyaw Phyo Aung, Lee Shi Yeo, Chean Leung Chong (Ripas Hospital).

Brazil Vanessa Dina Palomino Castillo, Monique Moron Munhoz, Gisele Moreira (Conjunto Hospitalar De Sorocaba), Luiz Carlos Barros De Castro Segundo, Salim Anderson Khouri Ferreira, Maíra Cassa Careta (Hospital Da Santa Casa De Misericórdia De Vitória), Stella Binna Kim, Alexandre Venancio De Sousa, Alyne Daltri Lazzarini Cury (Hospital De Caridade Sãfo De Paula), Gustavo Peixoto Soares Miguel, Ana Vega Carreiro De Freitas, Barbara Pereira Silvestre (Hospital Estadual Doutor Jayme Dos Santos Neves), Julia Guasti Pinto Vianna, Carolina Oliveira Felipe, Luis Alberto Valente Laufer (Hospital Estadual Doutor Jayme Santos Neves), Fernanda Altoe, Luana Ayres Da Silva, Marina Luiza Pimenta, Thiago Fernandes Giuriato, Paulo Alves Bezerra Morais, Jessica Souza Luiz (Hospital Estadual Dr Jayme Santos Neves), Rafael Araujo, Juliana Menegussi, Marisa Leal, Caio Vinícius Barroso de Lima, Luiza Sarmento Tatagiba, Antônio Leal (Hospital Infantil Nosa Senhora Da Gloria), Diogo Vinicius dos Santos, Gustavo Pereira Fraga, Romeo Lages Simoes (Hospital De Clinicas, University Of Campinas).

Cambodia Simon Stock (World Mate Emergency Hospital).
Cameroon Samuel Nigo, Juana Kabba, Tagang Ebogo Ngwa, James Brown (Mbingo Baptist Hospital).

Canada Sebastian King, Augusto Zani, Georges Azzie, Mohammed Firdouse, Sameer Kushwaha, Arnav Agarwal (The Hospital For Sick Children), Karen Bailey, Brian Cameron, Michael Livingston (McMaster Children's Hospital), Alexandre Horobjowsky, Dan L Deckelbaum, Tarek Razek (Centre for Global Surgery, McGill University Health Centre).

Chile Boris Marinkovic, Eugenio Grasset, Nicole D'aguzan (Hospital Del Salvador), Eugenio Grasset, Julio Jimenez, Roberto Macchiavello (Hospital Luis Tisne).

China Zhongtao Zhang, Wei Guo, Junyeong Oh, Fei Zheng (Beijing Friendship Hospital).

Colombia Irene Montes, Sebastian Sierra, Manuela Mendez (Clinica Ces), Maria Isabel Villegas, Maria Clara Mendoza Arango, Ivan Mendoza, (Clinica Las Vegas), Fred Alexander Naranjo Aristizã bal, Jaime Andres Montoya Botero, Victor Manuel Quintero Riaza (Hospital Pablo Tobon Uribe), Jakeline Restrepo, Carlos Morales, Maria Clara Mendoza Arango (Hospital Universitario San Vicente Fundacion), Herman Cruz, Alejandro Munera, Maria Clara Mendoza Arango (Ips Universitaria Clinica Leon Xiii).

Croatia Robert Karlo, Edgar Domini, Jakov Mihanovic (Zadar General Hospital), Mihael Radic, Kresimir Zamarin, Nikica Pezelj (General Hospital Sibenik).

Dominican Republic Manuel Hache-Marliere, Sylvia Batista Lemaire, Ruben Rivas (Cedimat - Centro De Diagnostico Medicina Avanzada, Laboratorio Y Telemedicina).

Egypt Ahmed Khyrallh, Ahamed Hassan, Gamal Shimy, Mohamed A Baky Fahmy (Al-Azher Universty Hospital); Ayman Nabawi, Mohamed Elfil, Mohamed Ghoneem, Muhammad El-Saied Ahmad Muhammad Gohar, Mohamed Asal, Mostafa Abdelkader, Mahmoud Gomah, Hayssam Rashwan, Mohamed Karkeet, Ahmed Gomaa (Alexandria Main University Hospital); Amr Hasan, Ahmed Elgebaly, Omar Saleh, Ahmad Abdel Fattah, Abdullah Gouda, Abd Elrahman Elshafay, Abdalla Gharib, Ahmed Menshawy, Mohammed Hanafy, Abdullah Al-Mallah, Mahmoud Abdulgawad, Mohamad Baheeg, Mohammed Alhendy, Ibrahim AbdelFattah, Abdalla Kenibar, Omar Osman, Mostafa Gemeah, Ahmed Mohammed, Abdalrahman Adel, Abdalla Gharib, Abdelrahman Mohammed, Abdelrahman Sayed, Mohamed Abozaid (Al-Hussein Hospital); Ahmed Hafez El-Badri Kotb, Ali Amin Ahmed Ata, Mohammed Nasr, Abdelrahman Alkammash, Mohammed Saeed, Nader Abd El Hamid, Attia Mohamed Attia, Ahmed Abd El Galeel, Eslam Elbanby, Khalid Salah El-Dien, Usama Hantour, Omar Alahmady, Billal Mansour, Amr Muhammad Elkorashy (Bab El-Shareia Hospital); Emad Mohamed Saeed Taha, Kholod Tarek Lasheen, Salma Said Elkolaly, Nehal Yosri Elsayed Abdel-Wahab, Mahmoud Ahmed Fathi Abozyed, Ahmed Adel, Ahmed Moustafa Saeed, Gehad Samir El Sayed, Jehad Hassan Youssif (Banha University Hospital); Soliman Magdy Ahmed, Nermeen Soubhy El-Shahat, Abd El-Rahman Hegazy Khedr (Belbes Central Hospital); Abdelrhman Osama Elsebaaye, Mohamed Elzayat, Mohamed Abdelraheim, Ibrahim Elzayat, Mahmoud Warda, Khaled Naser El Deen, Abdelrhman Essam Elnemr, Omar Salah, Mohamed Abbas, Mona Rashad, Ibrahim Elzayyat, Dalia Hemeda, Gehad Tawfik, Mai Salama, Hazem Khaled, Mohamed Seisa, (El Dawly Hospital - Mansoura); Kareem Elshaer, Abdelfatah Hussein, Mahmoud Elkhadrawi (El Mahalla General Hospital); Ahmed Mohamed Afifi, Osama Saadeldeen Ebrahim, Mahmoud Mohamed Metwally (El - Mataria Educational Hospital); Rowida Elmelegy, Diaa Moustafa Elbendary Elsawahly, Hisham Safa, Eman Nofal, Mohamed Elbermawy, Ahmed Abdelmotaleb Ghazy, Hisham Samih, Asmaa Abdelgelil, Sarah Abdelghany, Ahmed El Kholy, Metwally Aboraya, Fatma Elkady, Mahmoud Salma, Sarah Samy, Reem Fakher, Aya Aboarab, Ahmed Samir, Ahmed Sakr, Abdelrahman Haroun, Asmaa Abdel-Rahman Al-Aarag, Ahmed Elkholy, Sally Elshanwany (El-Menshawy Hospital); Esraa Ghanem (Elshohadaa Central Hospital); Ahmed Tammam, Ali Mohamed Hammad, 
Yousra El Shoura, Gehad El Ashal, Hosni Khairy (Kasr Alainy School Of Medicine); Sarah Antar, Sara Mehrez, Mahmoud Abdelshafy, Maha Gamal Mohamad Hamad, Mona Hosh, Emad Abdallah, Basma Magdy, Thuraya Alzayat, Elsayed Gamaly, Hossam Elfeki, Amany Abouzahra, Shereen Elsheikh, Fatimah I Elgendy (Mansoura University Hospitals); Fathia Abd El-Salam, Osama Seifelnasr, Mohamed Ammar, Athar Eysa, Aliaa Sadek, Aliaa Gamal Toeema, Aly Nasr, Mohamed Abuseif, Hagar Zidan, Sara Abd Elmageed Barakat, Nadin Elsayed, Yasmin Abd Elrasoul, Ahmed Elkelany, Mohamed Sabry Ammar, Mennat-Allah Mustafa, Yasmin Hegazy, Mohamed Etman, Samar Saad, Mahmoud Alrahawy, Ahmed Raslan, Mahmoud Morsi, Ahmed Rslan, Ahmed Sabry, Hager Elwakil, Heba Shaker, Hagar Zidan, Yasmin Abd-Elrasoul, Ahmed Elkelany (Menoufia University Hospitals); Hussein El-Kashef, Mohamed Shaalan, Areej Tarek (Minia University Hospital); Ayman Elwan, Ahmed Ragab Nayel, Mostafa Seif, Ayman Elwan, Doaa Emadeldin, Mohamed Ali Ghonaim, Ahmad Almallah, Ahmed Fouad, Eman Adel Sayma (New Damietta University Hospital); Ahmad Elbatahgy, Angham Solaiman El-Ma'doul, Ahmed Mosad, Hager Tolba, Diaa Eldin Abdelazeem Amin Elsorogy, Hassan Ali Mostafa, Amira Atef Omar, Ola Sherief Abd El Hameed, Ahmed Lasheen (Quweisna Central Hospital In Quweisna); Yasser Abd El Salam, Ashraf Morsi, Mohammed Ismail (Ras El Tin General Hospital); Hager Ahmed El-badawy, Mohamed A Amer, Ahmed Elkelany, Ahmed Elkelany, Ahmed Sabry El-Hamouly, Noura A. Attallah,Omnia Mosalum, Ahmed Afandy, Ahmed Mokhtar, Alaa Abouelnasr, Sara Ayad, Ramdan Shaker, Rokia Sakr, Ramadan Shaker, Mahmoud Amreia, Soaad Elsobky, Mohamed Mustafa, Ahmed Abo El Magd, Abeer Marey, Amr Tarek Hafez, Mohamed F Zalabia (Shebin Elkom Teaching Hospital, Menoufia); Mohamed Moamen Mohamed, Amr Fadel, Emad Ali Ahmed (Sohag University Hospital); Ahmad Ali, Mohammad Ghassan Alwafai, Abdullah Dwydar, Sara Kharsa, Ehab Mamdouh, Hatem El-Sheemy, Ibrahim AlYoussef, Abouelatta Khairy Aly, Ahmad Aldalaq, Ehab Alnawam, Dalia Alkhabbaz (Souad Kafafi University Hospital); Mahmoud Saad, Shady Hussein, Ahmed Abo Elazayem, Ahmed Meshref, Marwa Elashmawy, Mohammed Mousa, Ahmad Nashaat, Sara Ghanem, Zaynab M Elsayed, Aya Elwaey, Iman Elkadsh (Suez Canal University Hospitals); Mariam Darweesh, Ahmed Mohameden, Mennaallah Hafez (Suez General Hospital); Ahmed Badr, Assmaa Badwy, Mohamed Abd El Slam (Talla Central Hospital); Mohamed Elazoul, Safwat Al-Nahrawi, Lotfy Eldamaty, Fathee Nada, Mohamed Ameen, Aya Hagar, Mohamed Elsehimy, Mohammad Aboraya, Hossam Dawoud, Shorouk El Mesery, Abeer El Gendy, Ahmed Abdelkareem, Ahmed Safwan Marey, Mostafa Allam, Sherif Shehata, Khaled Abozeid, Marwa Elshobary, Ahmed Fahiem, Sameh Sarsik, Amel Hashish, Mohamed Zidan, Mohamed Hashish, Shaimaa Aql, Abdelaziz Osman Abdelaziz Elhendawy (Tanta University Hospital); Mohamed Husseini, Esraa Kasem, Ahmed Gheith, Yasmin Elfouly, Ahmed Ragab Soliman, Yasmein Ibrahim, Nesma Elfouly, Ahmed Fawzy, Ahmed Hassan, Mohammad Rashid, Abdallah Salah Elsherbiny, Basem Sieda, Nermin M Badwi, Mohammed Mustafa Hassan Mohammed, Osama Mohamed, Mohammad Abdulkhalek Habeeb (Zagazig University Hospitals).

Ethiopia Mengistu Worku, Nichole Starr (Dessie Referral Hospital), Semay Desta, Sahlu Wondimu, Nebyou Seyoum Abebe (Minilik Ii Hospital), Efeson Thomas, Frehun Ayele Asele, Daniel Dabessa (Myungsung Christian Medical Center), Nebiyou Seyoum Abebe, Abebe Bekele Zerihun (Tikur Anbessa Hospital).

Finland Panu Mentula, Ari Leppäniemi, Ville Sallinen (Helsinki University Central Hospital).

France Aurelien Scalabre, Fernanda Frade, Sabine Irtan (Trousseau Hospital Sorbonnes Universités, Upmc Univ Paris), Vivien Graffeille, Elodie Gaignard, Quentin Alimi (Chu De Rennes), Quentin Alimi, Vivien Graffieille, Elodie Gaignard (Fr Rennes University), Olivier Abbo, Sofia Mouttalib, Ourdia Bouali (Hopital Des Enfants), Erik Hervieux, Yves Aigrain, Nathalie Botto (Hopital Necker Enfants Malades), Alice Faure, Lucile Fievet, Nicoleta Panait (Hopitâl Nord), Emilie
Eyssartier, Francoise Schmitt, Guillaume Podevin (Pediatric Surgery Department, University Hospital Of Angers, France), Valentine Parent, Amandine Martin, Alexis Pierre Arnaud (Rennes University Hospital), Cecile Muller, Arnaud Bonnard, Matthieu Peycelon (Robert Debré Children University Hospital).

Ghana Francis Abantanga, Kwaku Boakye-Yiadom, Mohammed Bukari (Komfo Anokye Teaching Hospital), Frank Owusu (Offinso District Hospital), Joseph Awuku-Asabre, Stephen Tabiri, Lemuel Davies Bray (University For Development Studies, School Of Medicine And Health Sciences, General Surgery Department,Tamale Teaching Hospital).

Greece Dimitrios Lytras, Kyriakos Psarianos, Anastasia Bamicha (Achillopoyleio General Hospital Of Volos), Eirini Kefalidi (Attikon General Hospital), Georgios Gemenetzis (Attikon University Hospital), Christos Dervenis, Nikolaos Gouvas, Christos Agalianos (Konstantopouleio General Hospital Of Athens), Michail Kontos, Gregory Kouraklis, Dimitrios Karousos (Laiko University Hospital), Stylianos Germanos, Constantinos Marinos (Larissa General Hospital), Christos Anthoulakis, Nikolaos Nikoloudis, Nikolaos Mitroudis (Serres General Hospital).

Guatemala Gustavo Recinos, Sergio Estupinian, Walter Forno (Hospital De Accidentes Ceibal), José René Arévalo Azmitia (Hospital General De Enfermedades, Cirugia De Emergencia, Instituto Guatemalteco De Seguridad Social), Carla Cecilia Ramãrez Cabrera (Hospital General De Enfermedades, Servicio De Cirugia Abdominal, Instituto Guatemalteco De Seguridad Social), Romeo Guevara, Maria Aguilera, Napoleon Mendez, Cesar Augusto Azmitia Mendizabal, Pablo Ramazzini, Mario Contreras Urquizu (Hospital General San Juan De Dios), Fernando Tale, Rafael Soley, Emanuel Barrios, Emmanuel Barrios (Hospital Juan Jose Arevalo Bermejo), Daniel Estuardo Marroquín Rodríguez, Carlos Iván Pérez Velásquez, Sara María Contreras Mérida (Hospital Regional De Retalhuleu), Francisco Regalado, Mario Lopez, Miguel Siguantay (Hospital Roosevelt, Guatemala).

Hong Kong Fong Yee Lam, Kylie Joan-yi Szeto, Charing Cheuk Ling Szeto, Wing Sum Li, Kieran Ka Kei Li, Man Fung Leung, Tony Mak, Simon Ng (Prince of Wales Hospital).

India SS Prasad, Anand Kirishnan, Nidhi Gyanchandani (KMC Hospital), Bylapudi Seshu Kumar, Muthukumaran Rangarajan (Kovai Medical Centre \& Hospital), Sriram Bhat, Anjana Sreedharan, S.V. Kinnera (Kasturba Medical College), Yella Reddy, Caranj Venugopal, Sunil Kumar (Pes Institute Of Medical Sciences \& Research), Abhishek Mittal (Safdarjung Hospital,New Delhi), Shravan Nadkarni, Harish Neelamraju Lakshmi, Puneet Malik (Sawai Man Singh Medical College \& Hospitals, Jaipur, Rajasthan), Neel Limaye, Srinivas Pai, Pratik Jain (Sdm College Of Medical Sciences And Hospital), Monty Khajanchi, Savni Satoskar, Rajeev Satoskar (Seth Gordhandas Sunderdas Medical College And King Edward Memorial Hospital), Abid Bin Mahamood (Travancore Medical College Hospital).

Indonesia Eldaa Prisca Refianti Sutanto, Daniel Ardian Soeselo, Chintya Tedjaatmadja (Atmajaya Hospital), Fitriana Nur Rahmawati, Radhian Amandito, Maria Mayasari (Dr Cipto Mangunkusumo General Hospital, Jakarta).

Iraq Ruqaya Kadhim Mohammed Jawad Al-Hasani, Hasan Ismael Ibraheem Al-Hameedi, Hasan Ismael Ibraheem, Israa Abdullah Aziz Al-Azraqi (Alsader Medical City), Lubna Sabeeh, Rahma Kamil, Marwan Shawki (Baghdad Medical City), Muwaffaq Mezeil Telfah (Department Of Surgery, College Of Medicine, University Of Mosul, Al-Jumhoori Teaching Hospital).

Ireland Amoudtha Rasendran, Jacqueline Sheehan, Robert Kerley, Caoimhe Normile, Richard William Gilbert, Jiheon Song, Mohamed Dablouk, Linnea Mauro, Mohammed Osman Dablouk, Michael Hanrahan, Paul Kielty, Eleanor Marks (Cork University Hospital), Simon Gosling, Michelle Mccarthy, Amoudtha Rasendran (Cork University Hospital \& University College Cork), Diya Mirghani, Syed Altaf Naqvi, Chee Siong Wong (Limerick University Hospital), Siyi Chung, Reuban D'cruz, Ronan Cahill (Mater Misericordiae University 
Hospital), Simon George Gosling, Michelle Mccarthy, Amoudtha Rasendran, Ciara Fahy, Jiheon Song, Michael Hanrahan, Diana Duarte Cadogan, Anna Powell, Richard Gilbert, Caroline Clifford, Caoimhe Normile, Aoife Driscoll (Mercy University Hospital), Stassen Paul, Chris Lee, Ross Bowe (Midlands Regional Hospital Mullingar), William Hutch, Michael Hanrahan (University College Cork), Helen Mohan, Maeve O'neill, Kenneth Mealy (Wexford General Hospital).

Italy Piergiorgio Danelli, Andrea Bondurri, Anna Maffioli (Azienda Ospedaliera Luigi Sacco - Polo Universitario), Mario Pasini, Giacomo Pata, Stefano Roncali (Azienda Ospedaliera Spedali Civili Di Brescia Chirurgia Generale), Paolo Silvani, Michele Carlucci, Roberto Faccincani (Irccs Ospedale San Raffaele), Luigi Bonavina, Yuri Macchitella, Chiara Ceriani (University of Milan, IRCCS Policlinico San Donato), Gregorio Tugnoli, Salomone Di Saverio, Khaled Khattab (Maggiore Hospital), Miguel Angel Paludi, Domenica Pata, Luigi Maria Cloro (Nicola Giannettasio Hospital), Andrea Allegri, Luca Ansaloni, Federico Coccolini (Papa Giovanni Xxiii Hospital), Ezio Veronese, Luca Bortolasi, Alireza Hasheminia (San Bonifacio Hospital), Giacomo Nastri, Massimiliano Dal Canto, Stefano Cucumazzo (Santa Croce Hospital), Francesco Pata, Angelo Benevento, Gaetano Tessera (Sant'Antonio Abate Hospital, Gallarate), Pier Paolo Grandinetti, Alessio Maniscalco, Giovanni Luca Lamanna (Santi Benvenuto E Rocco Hospital Asur), Luca Turati, Giovanni Sgroi, Emanuele Rausa (Treviglio Hospital), Roberta Villa, Michela Monteleone, David Merlini (Unita' Di Chirurgia D’urgenza Azienda Ospedaliera Salvini), Federico Coccolini, Luca Ansaloni, Andrea Allegri (Unit Of General Surgery I, Papa Giovanni Xxiii Hospital), Veronica Grassi, Roberto Cirocchi, Alban Cacurri (University Of Perugia).

Libya Hamza Waleed, Ahmed Diab, Fathi Elzowawi (Misurata Central Hospital).

Lithuania Mantas Jokubauskas, Karolis Varkalys, Donatas Venskutonis (Kaunas Clinical Hospital), Robertas Pranevicius, Viktorija Ambrozeviciute (Klaipedas Seaman Hospital), Simona Juciute, Austė Skardžiukaitè (Lietuvos Sveikatos Mokslų Universitetas), Donatas Venskutonis, Saulius Bradulskis, Linas Urbanavicius, Aiste Austraite, Romualdas Riauka, Justas Zilinskas, Zilvinas Dambrauskas (Lithuanian University Of Health Sciences), Paulius Karumnas, Zigmantas Urniezius, Reda Zilinskiene (Republic Hospital Of Kaunas), Anele Rudzenskaite (Republic Hospital Of Panevezys), Ausrine Usaityte, Margarita Montrimaite, Nerijus Kaselis (Republic Klaipeda Hospital), Andrius Strazdas, Kristijonas Jokubonis (Stasys Kudirka Regional Hospital Of Alytus), Kornelija Maceviciute, Virgilijus Beisa, Tomas Poskus, Kestutis Strupas, Erikas Laugzemys (Vilnius University, Center Of Abdominal Surgery), Andrej Kolosov, Valdemaras Jotautas, Ignas Rakita (Vilnius University HospitalSantariskiu Clinics), Saulius Mikalauskas, Darius Kazanavicius, Rokas Rackauskas, Kestutis Strupas, Tomas Poskus, Virgilijus Beisa (Vilnius University Hospital Santariskiu Klinikos), Ritauras Rakauskas, Egle Preckailaite (Vsi Jonavos Ligonine).

Malawi Ross Coomber, Kenneth Johnson, Jennifer Nowers (Queen Elizabeth Hospital).

Malaysia Dineshwary Periasammy, Afizah Salleh, Andre Das (Hospital Kajang), Reuben Goh Ern Tze, Milaksh Nirumal Kumar, Nik Azim Nik Abdullah (Sarawak General Hospital), Nik Ritza Kosai, Mustafa Taher, Reynu Rajan (Universiti Kebangsaan Malaysia Medical Centre), Hoong Yin Chong, April Camilla Roslani, Cheng Chun Goh (University Malaya Medical Centre).

Malta Marija Agius, Elaine Borg, Maureen Bezzina, Roberta Bugeja, Martinique Vella-Baldacchino, Andrew Spina, Josephine Psaila (Mater Dei Hospital, Malta).

Martinique Helene Francois-Coridon, Cecilia Tolg, Jean-Francois Colombani (Department Of Pediatric Surgery, Mother And Children's Hospital, University Hospital Of Martinique).

Mexico Carmina Diaz-Zorrilla, Antonio Ramos-De La Medina, Samantha Corro-Diaz Gonzalez (Hospital Español de Veracruz).
Mozambique Mário Jacobe, Domingos Mapasse, Elizabeth Snyder (Hospital Central Maputo).

New Zealand Ramadan Oumer, Mohammed Osman (Whangarei Hospital, Northland District Health Board).

Nigeria Aminu Mohammad, Lofty-John Anyanwu, Abdulrahman Sheshe (Aminu Kano Teaching Hospital), Alaba Adesina, Olubukola Faturoti, Ogechukwu Taiwo (Babcock University Teaching Hospital), Muhammad Habib Ibrahim, Abdulrasheed A Nasir, Siyaka Itopa Suleiman (Federal Medical Centre, Birnin Kebbi), Adewale Adeniyi, Opeoluwa Adesanya, Ademola Adebanjo (Federal Medical Centre), Roland Osuoji, Kazeem Atobatele, Ayokunle Ogunyemi, Omolara Williams, Mobolaji Oludara, Olabode Oshodi (Lagos State University Teaching Hospital), Adesoji Ademuyiwa, AbdulRazzaq Oluwagbemiga Lawal, Felix Alakaloko, Olumide Elebute, Adedapo Osinowo, Christopher Bode(Lagos University Teaching Hospital), Abidemi Adesuyi (National Hospital Abuja), Adesoji Tade, Adeleke Adekoya, Collins Nwokoro (Olabisi Onabanjo University Teaching Hospital),Omobolaji O Ayandipo, Taiwo Akeem Lawal, Akinlabi E Ajao (University College Hospital),Samuel Sani Ali, Babatunde Odeyemi, Samson Olori (University of Abuja Teaching Hospital),Ademola Popoola, Ademola Adeyeye, James Adeniran (University of Ilorin Teaching Hospital).

Norway William J. Lossius (Department Of Gastrointestinal Surgery, St. Olavs Hospital, Trondheim University Hospital), Ingemar Havemann (Soerlandet Hospital Kristiansand), Kenneth Thorsen, Jon Kristian Narvestad, Kjetil Soreide (Stavanger University Hospital), Trude Beate Wold, Linn Nymo (University Hospital Of North Norway, Troms).

Oman Mohammed Elsiddig, Manzoor Dar (Sohar Hospital).

Pakistan Kamran Faisal Bhopal, Zainab Iftikhar, Muhammad Mohsin Furqan (Bahawal Victoria Hospital), Bakhtiar Nighat, Masood Jawaid, Abdul Khalique (Dow University Hospital), Ahsan Zil-E-Ali, Anam Rashid (Fatima Memorial Hospital), Hasnain Abbas Dharamshi, Tahira Naqvi, Ahmad Faraz (Karachi Medical And Dental College, Abbasi Shaheed Hospital), Abdul Wahid Anwar, Tahir Muhammad Yaseen, Ghina Shamim Shamsi, Ghina Shamsi, Tahir Yaseen, Wahid Anwer (The Indus Hospital).

Paraguay Horacio Paredes Decoud, Omar Aguilera, Ismael Isaac Zelada Alvarez, Juan Marcelo Delgado, Gustavo Miguel Machain Vega, Helmut Alfredo Segovia Lohse (Hospital De Clínicas).

Peru Wendy Leslie Messa Aguilar, Jose Antonio Cabala Chiong, Ana Cecilia Manchego Bautista (Carlos Alberto Seguin Escobedo National Hospital. Essalud), Eduardo Huaman, Sergio Zegarra, Rony Camacho (Hospital Necional Guillermo Almenara), Jose María Vergara Celis, Diego Alonso Romani Pozo (Hospital De Emergencias Pediatricas), José Hamasaki, Edilberto Temoche, Jaime Herrera-Matta (Hospital De Policia), Carla Pierina García Torres, Luis Miguel Alvarez Barreda, Ronald Renato Barrionuevo Ojeda (Hospital Goyeneche), Octavio Garaycochea (Hospital Ii -1 Minsa Moyobamba), Melanie Castro Mollo, Mitchelle Solange De Fã Tima Linares Delgado, Francisco Fujii (Hospital Maria Auxiliadora), Ana Cecilia Manchego Bautista, Wendy Leslie Messa Aguilar, Jose Antonio Cabala Chiong (Hospital Nacional Carlos Alberto Seguin), Susana Yrma Aranzabal Durand, Carlos Alejandro Arroyo Basto, Nelson Manuel Urbina Rojas (Hospital Nacional Edgardo Rebagliati Martins-Essalud), Sebastian Bernardo Shu Yip, Ana Lucia Contreras Vergara, Andrea Echevarria Rosas Moran, Giuliano Borda Luque, Manuel Rodriguez Castro, Ramon Alvarado Jaramillo (Hospital Nacional Cayetano Heredia), George Manrique Sila, Crislee Elizabeth Lopez, Mardelangel Zapata Ponze De Leon, Massiell Machaca, Ronald Coasaca Huaraya, Andy Arenas, Crislee López, Clara Milagros Herrera Puma, Wilfredo Pino, Christian Hinojosa, Melanie Zapata Ponze De Leon, Susan Limache, George Manrrique Sila, Layza-Alejandra Mercado Rodriguez (Hospital Regional Honorio Delgado Espinoza).

Portugal Renato Melo, Jose Costa-Maia, Nuno Muralha (Servico De Cirurgia Geral - Centro Hospitalar Sao Joao - Porto).

Reunion Frederique Sauvat (Chu Reunion). 
Romania Ionasc Dan, Mircea Hogea, Pandi Eduard (Emergency Clinical Hospital Brasov), Razvan-Matei Bratu, Mircea Beuran, IonutBogdan Diaconescu, Bogdan-Valeriu Martian, Florin-Mihail Iordache, Mihaela Vartic (Emergency Clinical Hospital Bucharest), Lucian Corneliu Vida, Liviu Iuliu Muntean, Aurel Sandu Mironescu (Spitalul Clinic De Copii Brasov).

Rwanda Vizir Jean Paul Nsengimana (Chuk), Alice Niragire, Jean De La Croix Allen Ingabire, Eugene Niyirera (University Teaching Hospital Of Kigali)

San Marino Nicola Zanini, Elio Jovine, Giovanni Landolfo (San Marino State Hospital).

Saudi Arabia Ibrahim N. Alomar, Saleh A. Alnuqaydan, Abdulrahman M. Altwigry (Buraydah Central Hospital), Moayad Othman, Nohad Osman (Imam Abdulrahman Al Faisal Hospital), Enas Alqahtani (King Abdulaziz Hospital Al Ahsa National Guard), Mohammed Alzahrani, Rifan Alyami, Emad Aljohani (King Abdulaziz Medical City), Ibrahim Alhabli, Zaher Mikwar, Sultan Almuallem (King Abdulaziz Medical City (King Khalid National Guard Hospital, Jeddah), Emad Aljohani, Rifan Alyami, Mohammed Alzahrani (King Abdulaziz Medical City, Riyadh), Abrar Nawawi, Mohamad Bakhaidar, Ashraf A. Maghrabi, Mohammed Alsaggaf, Murad Aljiffry, Abdulmalik Altaf, Ahmad Khoja, Alaa Habeebullah, Nouf Akeel (Department of Surgery, Faculty of Medicine, King Abdulaziz University, Jeddah, Saudi Arabia), Nashat Ghandora, Abdullah Almoflihi, Abdulmalik Huwait (King Fahad General Hospital), Abeer Al-shammari, Mashael Al-Mousa (King Fahad Hospital), Masood Alghamdi, Walid Adham, Bandar Albeladi, Muayad Ahmed Alfarsi, Atif Mahdi, Saad Al Awwad (King Fahd Hospital), Afnan Altamimi, Thamer Nouh, Mazen Hassanain (King Khaled University Hospital, King Saud University), Salman Aldhafeeri, Nawal Sadig, Osama Algohary (King Khalid General Hospital), Mohannad Aledrisy, Ahmad Gudal, Ahmad Alrifaie (King Khalid National Guard Hospital), Mohammed AlRowais, Amani Althwainy (Department of Surgery, King Saud University), Alaa Shabkah, Uthman Alamoudi, Mawaddah Alrajraji (National Guard Hospital), Basim Alghamdi, Saud Aljohani, Abdullah Daqeeq (Rcymc), Jubran J Al-Faifi (Security Forces Hospital).

South Africa Vicky Jennings, Nyawira Ngayu, Rachel Moore (Chris Hani Baragwanath Academic Hospital), Victor Kong (Edendale Hospital), Hayden Kretzmann, Katie Connor, Daniel Nel (Frere Hospital), Colleen Sampson, Richard Spence, Eugenio Panieri (Groote Schuur), Sarah Rayne, Nosisa Sishuba (Helen Joseph Hospital, Department Of Surgery, University Of The Witwatersrand), Myint Tun, Albert Mohale Mphatsoe, Jo-Anne Carreira (Leratong Hospital), Ella Teasdale, Mark Wagener (Ngwelezana Hospital), Stefan Botes, Danelo Du Plessis (Rob Ferreira Hospital).

Spain Fernando Fernandez-Bueno (Hospital Central De La Defensa Gomez Ulla), Jose Aguilar-Jimenez, Jose Andres Garcia-Marin (Hospital Morales Meseguer. Sms), Lorena Solar García, Luis Joaquín García Florez, Rubén Darío Arias Pacheco (Hospital San Agustín), Janet Pagnozzi, Jimy Harold Jara Quezada, Jose Luis Rodicio, German Minguez, Raquel Rodríguez-Uría, Paul Ugalde, Camilo Lopez-Arevalo, Luis Barneo, Jessica Patricia Gonzales Stuva (Hospital Universitario Central De Asturias), Irene Ortega-Vazquez, Lorena Rodriguez, Norberto Herrera (Severo Ochoa University Hospital).

Sri Lanka Prasad Pitigala Arachchi, Wanigasekara Senanayake Mudiyanselage Kithsiri Janakantha Senanayake, Lalith Asanka Jayasooriya Jayasooriya Arachchige (Department Of General Surgery, Teaching Hospital Kandy), Sivasuriya Sivaganesh, Dulan Irusha Samaraweera, Vimalakanthan Thanusan (National Hospital Of Sri Lanka).

Sudan Ahmed Elgaili Khalid Musa, Reem Mohammed Hassan Balila, Mohamed Awad Elkarim Hamad Mohamed (Ibrahim Malik Teaching Hospital), Hussein Ali, Hagir Zain Elabdin, Alaa Hassan(Jarash International Specialized Hospital), Sefeldin Mahdi, Hala Ahmed, Sahar Abdoun Ishag Idris (Khartoum Teaching Hospital), Makki
Elsayed, Mohammed Elsayed, Mohamed Mahmoud (Omdurman Teaching Hospital).

Sweden Magnus Boijsen, Per-Olof Lundgren (Capio St Goran Hospital), Ulf Gustafsson, Ali Kiasat (Danderyds Hospital), Fredrik Wogensen, Fredrik Wogensen, Emma Jurdell, Anders Thorell (Department Of Surgery, Ersta Hospital, Stockholm), Hildur Thorarinsdottir, Maria Utter (Helsingborgs Lasarett), Sami Martin Sundstrom (Hudiksvall Sjukhus), Cecilia Wredberg, Ann Kjellin (Karolinska Universitetssjukhuset), Johanna Nyberg, Bjorn Frisk (Skaraborg Hospital Skovde), Malin Sund, Linda Andersson, Ulf Gunnarsson (Department Of Surgical And Perioperative Sciences, Umea University and Umea University Hospital), Yücel Cengiz, Sandra Ahlqvist, Ida Björklund (Sundsvall Hostpital) Hanna Royson, Per Weber (Vaexjoe Central Hospital), Hans-Ivar Pahlsson, Eva Borin (Visby Hospital, Department Of Surgery), Maria Hjertberg (Vrinnevi Hospital), Hanna Royson, Per Weber (Vaxjo Central Hospital).

Switzerland Roger Schmid, Debora Schivo, Vasileios Despotidis (Bürgerspital Solothurn), Stefan Breitenstein, Ralph F Staerkle, Erik Schadde (Kantonsspital Winterthur), Fabian Deichsel, Alexandra Gerosa, Antonio Nocito (Kantonsspital Baden), Dimitri Aristotle Raptis, Barbara Mijuskovic, Markus Zuber, Lukas Eisner (Kantonsspital Olten), Swantje Kruspi, Katharina Beate Reinisch, Christin Schoewe (Kreisspital Fuer Das Freiamt Muri Ag), Allan Novak, Adrian F. Palma, Gerfried Teufelberger (Kreisspital Muri, Department Of Surgery).

Tanzania Msafiri Kimaro, Rachel King (Mbalizi Christian Designated Hospital)

Turkey Ali Zeynel Abidin Balkan, Mehmet Gumar, Mehmet Ali Yavuz (Harran University Research And Treatment Hospital), Ufuk Karabacak, Gokhan Lap, Bahar Busra Ozkan (Ondokuz Mayis University, Medical Faculty), Bahar Busra Ozkan, Murat Karakahya (Ordu University Training And Research Hospital).

United Kingdom Ryan Adams, Robert Morton, Liam Henderson, Ruth Gratton, Keiran David Clement, Kate Yu-Ching Chang, David Mcnish, Ryan Mcintosh, William Milligan (Aberdeen Royal Infirmary), Brendan Skelly, Hannah Anderson-Knight, Roger Lawther (Altnagelvin Area Hospital), Jemina Onimowo, Veereanna Shatkar, Shivanee Tharmalingam (Barking, Havering And Redbridge University Hospitals Trust (Queens Hospital, Romford), Evelina Woin, Tessa Fautz, Oliver Ziff (Barnet General Hospital), Shiva Dindyal, Sam Arman, Shagorika Talukder, Sam Arman, Vijay Gadhvi, Shagorika Talukder (Basildon And Thurrock University Foundation Trust), Luen Shaun Chew, Jonathan Heath (Blackpool Victoria Teaching Hospitals), Natalie Blencowe, Sally Hallam, Katherine Gash (Bristol Royal Infirmary), Gurdeep Singh Mannu, Dimitris-Christos Zachariades, Ailsa Claire Snaith (Buckinghamshire NHS Trust), Thusitha Sampath Hettiarachchi, Arjun Nesaratnam, James Wheeler (Cambridge University Hospitals NHS Foundation Trust), Darragh McCullagh, Joshua Michael Clements, Ata Khan (Causeway Hospital), Foteini Koumpa, Christina Neophytou, Jessica Roth, Wai Cheong Soon, Mohammed Deputy, Ahmed Ahmed, Annelisse Ashton, Joe Vincent, Jack Almy, Taufiq Khan, John Lee Y Allen, Charlotte Jane Mcintyre, Dominic Charles Marshall (Charing Cross Hospital, Imperial College Healthcare NHS Trust), Mark Sykes, Nebil Behar, Harriet Jordan (Chelsea And Westminster Hospital), Yaseen Rajjoub, Thomas Sherman (Cheltenham General Hospital), Timothy White, Anna Watts, Rohan Ardley (Chesterfield Royal Hospital NHS Foundation Trust), Tan Arulampalam, Apar Shah, Damien Brown (Colchester Hospital University NHS Foundation Trust), Emma Blower, Paul Sutton, Konstantinos Gasteratos, Dale Vimalachandran (Countess Of Chester Hospital), Cathy Magee, Gareth Irwin, Andrew Mcguigan (Craigavon Area Hospital), Stephen Mcaleer, Clare Morgan (Daisy Hill Hospital), Sarah Braungart (Department Of Paediatric Surgery, Leeds General Infirmary), Kirsten Lafferty, Peter Labib, Andrei Tanase, Clodagh Mangan, Lillian Reza, Lillian Reza, Andrei Tanase, Clodagh Mangan (Derriford Hospital), Helen Woodward, Craig Gouldthorpe, Megan Turner (Diana Princess Of 
Wales Hospital), Jonathan R L Wild, Tom AM Malik, Victoria K Proctor (Doncaster Royal Infirmary NHS Foundation Trust), Kalon Hewage, James Davies (Dorset County Hospital), Andre Dubois, Sayed Sarwary, Ali Zardab, Alan Grant, Robert Mcintyre (Dr Grays Hospital), Yogendra Praveen Mogan, Weiguang Ho, Bryon Frankie Hon Khi Chong (Dumfries And Galloway Royal Infirmary), Shirish Tewari, Gemma Humm, Eriberto Farinella (East And North Hertfordshire NHS Trust Lister Hospital) Nigel J Hall, Naomi J Wright, Christina P Major (Evelina Children's Hospital), Thelma Xerri, Phoebe De Bono, Jasim Amin, Mustafa Farhad, John F. Camilleri-Brennan, Andrew G N Robertson, Thelma Xerri, Joanna Swann, James Richards, Jasim Amin, Aijaz Jabbar, Phoebe De Bono, Myranda Attard, Hannah Burns, Euan Macdonald, Matthew Baldacchino, Jennifer Skehan, Julian CamilleriBrennan (Forth Valley Royal Hospital), Tom Falconer Hall, Madelaine Gimzewska, Greta Mclachlan (Frimley Park Hospital), Jamie Shah, James Giles (George Elliot Hospital), Selina Chiu, Beatrix Weber, Selina Man Yeng Chiu, Saskia Highcock (Gilbert Bain Hospital), Maleeha Hassan, William Beasley, Apostolos Vlachogiorgos, Stephen Dias, Geta Maharaj, Rosie Mcdonald (Glangwili General Hospital), Alisdair Macdonald, Paul Witherspoon, Alan Baird (Glasgow Southern General Hospital), Panchali Sarmah, Nikki Green, Haney Youssef (Good Hope Hospital), Kate Cross, Clare M Rees, Bernard Van Duren (Great Ormond Street Hospital For Children NHS Foundation Trust), Emma Upchurch (Great Western Hospital), Khurram Khan, Haytham Abudeeb, Ahmed Hammad (Hairmyres Hospital, NHS Lanarkshire), Sharad Karandikar, Doug Bowley, Ahmed Karim (Heart Of England Foundation Trust), Witold Chachulski, Liam Richardson, Giles Dawnay, Ben Thompson, Ajayesh Mistry, Aneel Bhangu, Millika Ghetia, Sudipta Roy, Ossama Al-Obaedi, Millika Ghetia, Kaustuv Das (Hereford County Hospital), Ash Prabhudesai, DM Cocker, Jessica Juliana Tan (Hillingdon Hospital), Robert Tyler, Filippo Di Franco, Shruti Ayyar (Hinchingbrooke Hospital), Sayinthen Vivekanantham, Shyam Gokani (Imperial College London), Michael Gillespie, Katrin Gudlaugsdottir (Inverclyde Royal Hospital), Theodore Pezas, Chelise Currow, Matthew Young-Han Kim (Ipswich Hospital NHS Trust), Amerdip Birring, Joanne Edwards, Ased Ali, Suparna Das, Madan Jha, Kieran Atkinson (James Cook University Hospital), Joshua Luck, Thomas Fozard, Michael Puttick (John Radcliffe Hospital), Yahya Salama, Rohi Shah, Ahmad Aboelkassem Ibrahem, Hamdi Ebdewi, Gianpiero Gravante, Saleem El-Rabaa (Kettering General Hospital), Henry Nnajiuba, Rebecca Allott, Aman Bhargava (King George Hospital), Zoe Chan, Zaffar Hassan (Kings College Hospital), Misty Makinde, David Hemingway, Ramzana Dean, Alexander Boddy, Ahmed Aber, Vijay Patel (Leicester Royal Infirmary), Jehangirshaw Parakh (Leighton Hospital - Mid Cheshire NHS Foundation Trust), Sunil Parthiban (Lister Hospital), Harmony Kaur Ubhi, Simon-Peter Hosein (Luton And Dunstable Hospital), Simon Ward, Kamran Malik (Macclesfield District General Hospital), Leifa Jennings, Tom Newton, Mirna Alkhouri, Min Kyu Kang, Christopher Houlden, Jonathan Barry (Morriston Hospital), Imtanan Raza, Alistair Farquharson, Sanjeet Bhattacharya (NHS Ayrshire), William Milligan, Kate Chang, Liam Henderson (NHS Grampian), Michael S J Wilson, Yan Ning Neo, Ibrahim Ibrahim, Emily Chan, Fraser S Peck, Pei J Lim, Alexander S North, Rebecca Blundell, Adam Williamson (Ninewells Hospital, NHS), Dina Fouad, Ashish Minocha (Norfolk And Norwich University Hospital), Kathryn Mccarthy, Emma Court, Alice Chambers (North Bristol NHS Trust), Jenna Yee, Ji Chung Tham, Ceri Beaton (North Devon District Hospital), Una Walsh, Joseph Lockey, Salman Bokhari, Lara Howells, Megan Griffiths, Laura Yallop (Northwick Park Hospital), Shailinder Singh, Omar Nasher, Paul Jackson (Nottingham Children's Hospital At Queens Medical Centre Campus), Michael Puttick, Joshua Luck, Thomas Fozard (Oxford University Hospitals), Abdul Muiz Shariffuddin, Weng Chee Ho, Michael Sj Wilson, Gurpreet Pabla (Perth Royal Infirmary), Saed Ramzi, Shady Zeidan, Jennifer Doughty (Plymouth Hospitals NHS Trust), Sidhartha Sinha, Ross Davenport, Jason Lewis (Princess Alexandra Hospital), Leo Duffy, Elizabeth Mcaleer, Eleanor
Williams (Princess Of Wales Hospital), Robin Som, Omar Javed (Queen Elizabeth Hospital Woolwich), Matthew Boal, Nicola Harrison, Habib Tafazal, Omar Javed, Tom Brogden, Dmitri Nepogodiev, Ewen Griffiths (Queen Elizabeth Hospital Birmingham) Rhalumi Daniel Obute, Thomas E Glover, David J Clark (Queen Elizabeth Hospital King's Lynn), Mohamed Boshnaq, Mansoor Akhtar, Pascale Capleton, Samer Doughan, Mohamed Rabie, Ismail Mohamed (Queen Elizabeth The Queen Mother Hospital), Duncan Samuel, Lauren Dickson, Matthew Kennedy, Eleanor Dempster, Emma Brown, Natalie Maple, Eimear Monaghan, Bernhard Wolf, Alicia Garland (Raigmore Hospital), Arthur Mcphee, David Anderson, Robert Anderson (Royal Alexandria Hospital), Sarah Hassan, Paul Sutton, Dave Smith (Royal Bolton Hospital), Jonathan Lund, Catherine Boereboom, Jennifer Murphy, Gillian Tierney, Samson Tou (Royal Derby Hospital), Eleanor Franziska Zimmermann, Neil James Smart, Andrea Marie Warwick (Royal Devon And Exeter National Health Service Foundation Trust), Theodora Stasinou, Ian Daniels, Kim Findlay-Cooper (Royal Devon \& Exeter NHS Foundation Trust), Stefan Mitrasinovic, Swayamjyoti Ray, Massimo Varcada, Rovan D'Souza, Sharif Omara (Royal Free Hospital), Matthew Spurr, Lucienne Parkinson, Anthony Hanks (Royal Glamorgan Hospital), Jennifer Ma, Emily Abington, Meera Ramcharn, Gethin Williams (Royal Gwent Hospital), Joseph Winstanley, Ewan D. Kennedy, Emily NW Yeung (Royal Hospital For Sick Children),Stuart J Fergusson, Catrin Jones, Stephen O'neill, Shujing Jane Lim, Ignatius Liew, Hari Nair, Cameron Fairfield, Julia Oh, Samantha Koh, Andrew Wilson, Catherine Fairfield (Royal Infirmary Of Edinburgh), Delran Anandkumar, Ashok Kirupagaran, Timothy F Jones, Hew Dt Torrance, Alexander J Fowler, Charmilie Chandrakumar, Priyank Patel, Syed Faaz Ashraf, Sonam M. Lakhani, Aaron Lawson Mclean, Sonia Basson (Royal London Hospital), Jeremy Batt, Catriona Bowman, Michael Stoddart, Natasha Benons (Royal United Hospital Bath), Clare Mason, Rebecca Harrison, John Quayle (Salford Royal NHS Foundation Trust), Tom Barker, Virginia Summerour, Edward Harper (Sandwell And West Birmingham Hospitals NHS Trust), Caroline Smith, Matthew Hampton (Sheffield Children's Hospital), Sophie K Pitt, Alex E Ward, Timothy O'Connor, Emily G Heywood, Thomas M Drake (Sheffield Teaching Hospitals NHS Foundation Trust), Abeed Chowdhury, Sina Hossaini, Nicholas Fs Watson (Sherwood Forest Hospitals NHS Foundation Trust), Doug Mckechnie, Ayaan Farah, Anita Chun (Southend University Hospital), Hoey Koh, Grace Lim, Graham Sunderland (Southern General Hospital), Laura Gould, Alice Chambers (Southmead Hospital), P C Munipalle, H Rooney, D R L Browning (Southmead Hospital, North Bristol NHS Trust), Bernadette Pereira, Kristof Nemeth, (St Georges Healthcare NHS Trust), Emily Decker, Stefano Giuliani, Aly Shalaby (St.George's Healthcare NHS Trust And University), Shafaque Shaikh, Chern Yan Tan, Ebrahim Y A Palkhi (St. James's University Hospital), Aleksandra Szczap, Swathikan Chidambaram, Chee Yang Chen, Kavian Kulasabanathan, Srishti Chhabra (St Mary's Hospital), Elisabeth Kostov, Philippe Harbord, James Barnacle (St. Mary's Hospital), Madan Mohan Palliyil, Mina Zikry, Johnathan Porter, Charef Raslan, Mohammed Saeed, Shazia Hafiz, Niksa Soltani, Katie Baillie (Stockport NHS Foundation Trust), Priyanka Singh, Shailee Sheth, Kishen Patel, Mahry Khalili, Jeesoo Choi, Matthew Benger (St Thomas' Hospital), Lucy Marples, Alastair Macfarlane, Ramesh Thurairaja (St. Thomas Hospital), Tamsin Boyce, Harriet Whewell, Elin Jones (The Royal Gwent Hospital), Francesca Th'ng, Nichola Robertson (The Royal Infirmary Of Edinburgh), Ahmad Mirza, Haroon Saeed, Simon Galloway (The University Hospital Of South Manchester), Gia Elena, Mohammad Afzal, Mohamed Zakir (United Lincolnshire Hospitals - Pilgrim Hospital), Peter Sodde, Charles Hand, Aiesha Sriram, Tamsyn Clark, Patrick Holton, Amy Livesey (University Hospital Coventry And Warwickshire), Yashashwi Sinha, Fahad Mujtaba Iqbal, Indervir Singh Bharj (University Hospital Of North Midlands), Adriana Rotundo, Cara Jenvey, Robert Slade (University Hospital Of North Staffordshire NHS Trust), David Golding, Samuel Haines, Ali Adel Ne'ma Abdullah, Thomas W Tilston, Dafydd 
Loughran, Danielle Donoghue, Lorenzo Giacci, Mohamed Ashur Sherif, Peter Harrison, Alethea Tang (University Hospital Of Wales), Deevia Kotecha (University Hospitals Leicester - Leicester Royal Infirmary), Mohamed Elshaer, Tomas Urbonas, Amjid Riaz, Annie Chapman, Parisha Acharya, Joseph Shalhoub (Watford General Hospital), Cathleen Grossart, David McMorran (Western General Hospital), Makhosini Mlotshwa, William Hawkins, Sofronis Loizides (Western Sussex Hospitals NHS Trust), Kandaswamy Krishna, Melanie Orchard, Chik Wai Ho (Weston General Hospital), Peter Thomson, Shahab Khan, Fiona Taylor, Jalak Shukla, Emma Elizabeth Howie (Whipps Cross University Hospital), Linda Macdonald, Olusegun Komolafe, Neil Mcintyre (Wishaw General Hospital), James Cragg, Jody Parker, Duncan Stewart (Wrexham Maelor Hospital), Luke Lintin, Julia Tracy, Tahir Farooq (Yeovil District Hospital).

United States George Molina, Haytham Kaafarani, Laura Luque (Massachusetts General Hospital), Robel Beyene, Jack Sava, Mark Scott (Medstar Washington Hospital Center), Mamta Swaroop, Raelene Kennedy (Northwestern Memorial Hospital), Ijeoma A Azodo, Daithi Heffernan, Tristen Chun, Andrew Stephen (The Rhode Island Hospital), Melanie Sion, Michael S. Weinstein, Viren Punja (Thomas Jefferson University Hospital), Nikolay Bugaev, Monica Goodstein, Shadi Razmdjou (Tufts Medical Center), Eric Etchill, Juan Carlos Puyana, Matthew Kesinger (University of Pittsburgh Medical Center - Presbyterian Hospital), Lena Napolitano, Kathleen To, Mark Hemmila (University of Michigan).

Zambia Oliver Todd, Edward Jenner, Ellen Hoogakker (St Francis Hospital).

Protocol Translation Jacky Hong Chieh Chen, Lawani Ismail, Dylan Roi, Eugenio Grasset Escobar.
Funding Funded by a DFID-MRC-Wellcome Trust Joint Global Health Trial Development Grant (MR/N022114/1), a Wellcome Trust Biomedical Vacation Scholarships (2015), and a National Institute of Health Research (NIHR) Global Health Research Unit Grant (NIHR 17-0799). The views expressed are those of the authors and not necessarily those of the National Health Service, the NIHR, or the UK Department of Health and Social Care.

\section{Compliance with ethical standards}

Disclosures GlobalSurg Collaborative have no conflicts of interest or financial ties to disclose.

Open Access This article is distributed under the terms of the Creative Commons Attribution 4.0 International License (http://creativeco mmons.org/licenses/by/4.0/), which permits unrestricted use, distribution, and reproduction in any medium, provided you give appropriate credit to the original author(s) and the source, provide a link to the Creative Commons license, and indicate if changes were made.

\section{Appendix}

\section{Management and outcome of appendectomy in high, middle and low income countries}

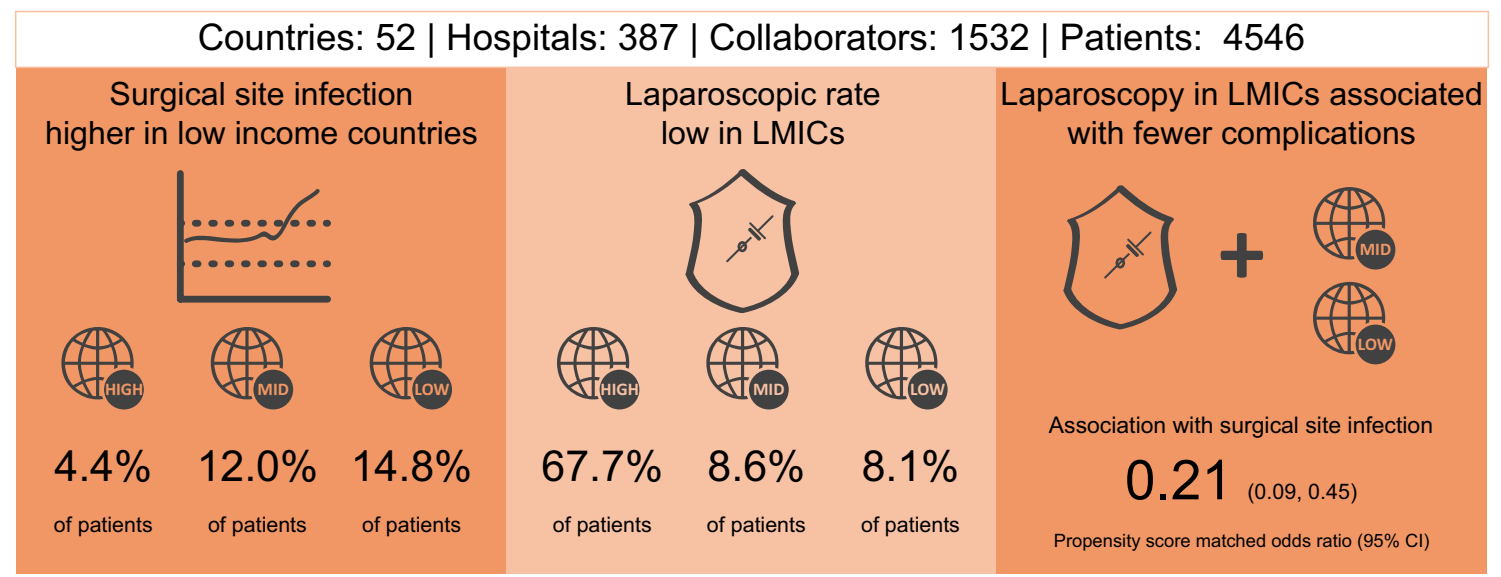

GlobalSurg Collaborative | globalsurg.org | @globalsurg 


\section{References}

1. Stewart B, Khanduri P, McCord C, Ohene-Yeboah M, Uranues S, Vega Rivera F, Mock C (2014) Global disease burden of conditions requiring emergency surgery. Br J Surg 101:e9-e22. https://doi.org/10.1002/bjs.9329

2. Alkire BC, Raykar NP, Shrime MG, Weiser TG, Bickler SW, Rose JA, Nutt CT, Greenberg SLM, Kotagal M, Riesel JN, Esquivel M, Uribe-Leitz T, Molina G, Roy N, Meara JG, Farmer PE (2015) Global access to surgical care: a modelling study. Lancet Glob Health 3:e316-e323. https://doi.org/10.1016/ S2214-109X(15)70115-4

3. Meara JG, Leather AJM, Hagander L, Alkire BC, Alonso N, Ameh EA, Bickler SW, Conteh L, Dare AJ, Davies J, Mérisier ED, El-Halabi S, Farmer PE, Gawande A, Gillies R, Greenberg SLM, Grimes CE, Gruen RL, Ismail EA, Kamara TB, Lavy C, Lundeg G, Mkandawire NC, Raykar NP, Riesel JN, Rodas E, Rose J, Roy N, Shrime MG, Sullivan R, Verguet S, Watters D, Weiser TG, Wilson IH, Yamey G, Yip W (2015) Global Surgery 2030: evidence and solutions for achieving health, welfare, and economic development. Lancet 386:569-624. https://doi. org/10.1016/S0140-6736(15)60160-X

4. GlobalSurg Collaborative (2016) Mortality of emergency abdominal surgery in high-, middle- and low-income countries. Br J Surg 103:971-988. https://doi.org/10.1002/bjs.10151

5. Ferris M, Quan S, Kaplan BS, Molodecky N, Ball CG, Chernoff GW, Bhala N, Ghosh S, Dixon E, Ng S, Kaplan GG (2017) The global incidence of appendicitis: a systematic review of population-based studies. Ann Surg. https://doi.org/10.1097/ SLA.0000000000002188

6. GBD Results: Appendicitis by country sociodemographic index. http://ghdx.healthdata.org/gbd-results-tool?params=gbdapi-2016-permalink/3c40df49b7377792f0fab1044d22d95e. Accessed 18 Oct 2017

7. Varadhan KK, Neal KR, Lobo DN (2012) Safety and efficacy of antibiotics compared with appendicectomy for treatment of uncomplicated acute appendicitis: meta-analysis of randomised controlled trials. BMJ 344:e2156

8. McCoy AC, Gasevic E, Szlabick RE, Sahmoun AE, Sticca RP (2013) Are open abdominal procedures a thing of the past? An analysis of graduating general surgery residents' case logs from 2000 to 2011. J Surg Educ 70:683-689. https://doi.org/10.1016/j. jsurg.2013.09.002

9. National Surgical Research Collaborative (2013) Multicentre observational study of performance variation in provision and outcome of emergency appendicectomy. Br J Surg 100:1240-1252. https://doi.org/10.1002/bjs.9201

10. Chao TE, Mandigo M, Opoku-Anane J, Maine R (2016) Systematic review of laparoscopic surgery in low- and middle-income countries: benefits, challenges, and strategies. Surg Endosc 30:110. https://doi.org/10.1007/s00464-015-4201-2

11. GlobalSurg Collaborative GlobalSurg 1 (2016) In: Globalsurg. http://globalsurg.org/projects/globalsurg-1/. Accessed 14 Dec 2016

12. Bhangu A, Fitzgerald JE, Fergusson S, Khatri C, Holmer H, Søreide K, Harrison EM (2014) Determining universal processes related to best outcome in emergency abdominal surgery: a multicentre, international, prospective cohort study. BMJ Open 4:e006239. https://doi.org/10.1136/bmjopen-2014-006239

13. Bhangu A, Kolias AG, Pinkney T, Hall NJ, Fitzgerald JE (2013) Surgical research collaboratives in the UK. Lancet Lond Engl 382:1091-1092. https://doi.org/10.1016/S0140-6736(13)62013-9

14. von Elm E, Altman DG, Egger M, Pocock SJ, Gøtzsche PC, Vandenbroucke JP (2007) The Strengthening the Reporting of Observational Studies in Epidemiology (STROBE) statement: guidelines for reporting observational studies. Lancet 370:14531457. https://doi.org/10.1016/S0140-6736(07)61602-X

15. Harris PA, Taylor R, Thielke R, Payne J, Gonzalez N, Conde JG (2009) Research Electronic Data Capture (REDCap)—A metadata-driven methodology and workflow process for providing translational research informatics support. J Biomed Inform 42:377-381. https://doi.org/10.1016/j.jbi.2008.08.010

16. Horan TC, Andrus M, Dudeck MA (2008) CDC/NHSN surveillance definition of health care-associated infection and criteria for specific types of infections in the acute care setting. Am J Infect Control 36:309-332. https://doi.org/10.1016/j.ajic.2008.03.002

17. GlobalSurg C (2016) Determinants of morbidity and mortality following emergency abdominal surgery in children in low-income and middle-income countries. BMJ Glob Health 1:e000091. https ://doi.org/10.1136/bmjgh-2016-000091

18. Wei H-B, Huang J-L, Zheng Z-H, Wei B, Zheng F, Qiu W-S, Guo W-P, Chen T-F, Wang T-B (2010) Laparoscopic versus open appendectomy: a prospective randomized comparison. Surg Endosc 24:266-269. https://doi.org/10.1007/s00464-009-0563-7

19. Aktimur R, Gokakin AK, Deveci K, Atabey M, Topcu O (2016) Oxidative stress markers in laparoscopic vs. open appendectomy for acute appendicitis: a double-blind randomized study. J Minim Access Surg 12:143-147. https://doi.org/10.4103/09729941.156203

20. Li X, Zhang J, Sang L, Zhang W, Chu Z, Li X, Liu Y (2010) Laparoscopic versus conventional appendectomy-a meta-analysis of randomized controlled trials. BMC Gastroenterol 10:129. https:// doi.org/10.1186/1471-230X-10-129

21. Bat O, Kaya H, Celik HK, Sahbaz NA (2014) Clinical results of laparoscopic appendectomy in patients with complicated and uncomplicated appendicitis. Int J Clin Exp Med 7:3478-3481

22. Horvath P, Lange J, Bachmann R, Struller F, Königsrainer A, Zdichavsky M (2016) Comparison of clinical outcome of laparoscopic versus open appendectomy for complicated appendicitis. Surg Endosc. https://doi.org/10.1007/s00464-016-4957-z

23. Taguchi Y, Komatsu S, Sakamoto E, Norimizu S, Shingu Y, Hasegawa H (2016) Laparoscopic versus open surgery for complicated appendicitis in adults: a randomized controlled trial. Surg Endosc 30:1705-1712. https://doi.org/10.1007/s00464-015-4453-x

24. E-Logbook I COSECSA. (2016) http://www.cosecsa.org/e-logbo ok-portal. Accessed 15 Dec 2016

25. Kong VY, Sartorius B, Clarke DL (2015) Acute appendicitis in the developing world is a morbid disease. Ann R Coll Surg Engl 97:390-395. https://doi.org/10.1308/003588415X1418125479 0608

26. Livingston EH, Woodward WA, Sarosi GA, Haley RW (2007) Disconnect between incidence of nonperforated and perforated appendicitis: implications for pathophysiology and management. Ann Surg 245:886-892. https://doi.org/10.1097/01.sla.00002 56391.05233.aa

27. Shrime MG, Dare A, Alkire BC, Meara JG (2016) A global country-level comparison of the financial burden of surgery. Br J Surg 103:1453-1461. https://doi.org/10.1002/bjs.10249

28. Raykar NP, Yorlets RR, Liu C, Goldman R, Greenberg SLM, Kotagal M, Farmer PE, Meara JG, Roy N, Gillies RD (2016) The how project: understanding contextual challenges to global surgical care provision in low-resource settings. BMJ Glob Health 1:e000075. https://doi.org/10.1136/bmjgh-2016-000075

29. Wei P-L, Chen C-S, Keller JJ, Lin H-C (2012) Monthly variation in acute appendicitis incidence: A 10-year nationwide populationbased study. J Surg Res 178:670-676. https://doi.org/10.1016/j. jss.2012.06.034

30. Price R, Sergelen O, Unursaikhan C (2013) Improving surgical care in Mongolia: a model for sustainable development. World J Surg 37:1492-1499. https://doi.org/10.1007/s00268-012-1763-1 